\title{
BH3 Mimetics for the Treatment of B-Cell Malignancies-Insights and Lessons from the Clinic
}

\author{
Victor S. Lin ${ }^{1,2,+(\mathbb{D})}$, Zhuo-Fan $X \mathrm{u}^{1,3,+}$, David C. S. Huang ${ }^{1,4}(\mathbb{D})$ and Rachel Thijssen ${ }^{1,4, *}$ \\ 1 The Walter and Eliza Hall Institute of Medical Research, 1G Royal Parade, Parkville 3052, Australia; \\ lin.v@wehi.edu.au (V.S.L.); xu.zh@wehi.edu.au (Z.-F.X.); huang_d@wehi.edu.au (D.C.S.H.) \\ 2 Faculty of Medicine, Dentistry and Health Sciences, University of Melbourne, Melbourne 3000, Australia \\ 3 School of Medicine, Tsinghua University, 30 Shuangqing Road, Haidian District, Beijing 100084, China \\ 4 Department of Medical Biology, University of Melbourne, Melbourne 3000, Australia \\ * Correspondence: thijssen.r@wehi.edu.au \\ + These authors contributed equally to this work.
}

Received: 13 October 2020; Accepted: 10 November 2020; Published: 12 November 2020

Simple Summary: B-cell malignancies, including chronic lymphocytic leukemia (CLL), non-Hodgkin lymphoma (NHL), and plasma cell dyscrasias, are significant contributors to cancer morbidity and mortality worldwide. The pathogenesis of many B-cell malignancies involves perturbations in the intrinsic pathway of apoptosis that allow cells to evade cell death. BH3 mimetics represent a class of anti-cancer agents that can restore the ability of cancer cells to undergo apoptosis. Venetoclax, a recently approved $\mathrm{BH} 3$ mimetic, has transformed the therapeutic landscape for CLL. Other BH3 mimetics are currently under development. This review summarizes the available data on existing $\mathrm{BH} 3$ mimetics and highlights both the rapidly expanding role of $\mathrm{BH} 3$ mimetics in the treatment of B-cell malignancies and the clinical challenges of their use.

\begin{abstract}
The discovery of the link between defective apoptotic regulation and cancer cell survival engendered the idea of targeting aberrant components of the apoptotic machinery for cancer therapy. The intrinsic pathway of apoptosis is tightly controlled by interactions amongst members of three distinct subgroups of the B-cell lymphoma 2 (BCL2) family of proteins. The pro-survival BCL2 proteins prevent apoptosis by keeping the pro-apoptotic effector proteins BCL2-associated X protein (BAX) and BCL2 homologous antagonist/killer (BAK) in check, while the BH3-only proteins initiate apoptosis by either neutralizing the pro-survival BCL2 proteins or directly activating the pro-apoptotic effector proteins. This tripartite regulatory mechanism is commonly perturbed in B-cell malignancies facilitating cell death evasion. Over the past two decades, structure-based drug discovery has resulted in the development of a series of small molecules that mimic the function of BH3-only proteins called the BH3 mimetics. The most clinically advanced of these is venetoclax, which is a highly selective inhibitor of BCL2 that has transformed the treatment landscape for chronic lymphocytic leukemia (CLL). Other BH3 mimetics, which selectively target myeloid cell leukemia 1 (MCL1) and B-cell lymphoma extra large (BCLxL), are currently under investigation for use in diverse malignancies. Here, we review the current role of $\mathrm{BH} 3$ mimetics in the treatment of CLL and other B-cell malignancies and address open questions in this rapidly evolving field.
\end{abstract}

Keywords: BH3 mimetics; venetoclax; apoptosis; BCL2; MCL1; BCLxL; B-cell malignancies; leukemia; lymphoma; myeloma

\section{Introduction}

Cell death is an important biological event that enables the clearance of unwanted or injured cells. Broadly speaking, cells can die in a highly regulated (or "programmed") fashion through the process 
of apoptosis or in an uncontrolled manner through the process of necrosis [1]. First described by Kerr, Wyllie, and Currie in 1972, apoptosis, which can be triggered by a range of internal and external stimuli, is characterized morphologically by shrinkage of the nucleus and mitochondria, encasement of cellular contents in membrane-bound apoptotic bodies, and rapid clearance of apoptotic bodies by adjacent phagocytes [2]. In contrast, necrosis, which usually results from acute cell trauma, is marked by swelling of the mitochondria, rupture of the plasma membrane, and spillage of inflammatory cellular contents into the surrounding tissue. Apoptosis has been found to play an essential role in the achievement of normal development [3,4] and the maintenance of tissue homeostasis [5,6]. Defects in the regulation of apoptosis can result in a number of diseases, including cancer [7].

To date, two distinct but convergent pathways to apoptosis have been identified in vertebrates: the extrinsic pathway and the intrinsic pathway (Figure 1). In contrast to the extrinsic pathway, which is initiated when certain death receptor ligands of the tumor necrosis factor (TNF) family (e.g., first apoptosis signal ligand [FAS-L], TNF) bind to their cognate death receptors (e.g., first apoptosis signal [FAS], TNF receptor [TNFR]) on the plasma membrane, resulting in the activation of caspase 8 , the intrinsic pathway is initiated by a diverse range of stress signals (e.g., DNA damage, growth factor deprivation). These stress signals disrupt the integrity of the outer mitochondrial membrane, triggering an event called mitochondrial outer membrane permeabilization (MOMP) [8]. Recognized as the "point of no return", MOMP causes the release of apoptogenic factors, including cytochrome c, second mitochondria-derived activator of caspase (SMAC) and Omi, from the intermembrane space of the mitochondria into the cytosol [9], where they facilitate the activation of caspase 9 in the apoptosome. The extrinsic and intrinsic pathways converge with initiator caspases (e.g., caspase 8, caspase 9) activating executioner caspases (e.g., caspase 3, caspase 7, caspase 6), which degrade cellular components and prepare dying cells for phagocytosis with minimal disruption to surrounding tissues [10].

\subsection{BCL2 Family Proteins: The Major Regulators of Apoptosis}

Commitment to the intrinsic pathway of apoptosis is governed by the B-cell lymphoma 2 (BCL2) family of proteins, which participate in a complex network of protein-protein interactions to regulate the integrity of the outer mitochondrial membrane. The BCL2 gene, encoding the founding member of this protein family, was initially identified from the breakpoint region of $t(14 ; 18)$, which is a recurrent chromosomal translocation in follicular lymphoma (FL) [11,12]. Driven by the immunoglobulin heavy chain gene promoter on chromosome 14, the translocated BCL2 gene becomes overexpressed in FL [13]. Subsequent studies discovered that the enforced expression of BCL2 in hematopoietic cells rendered them resistant to death induced by cytokine deprivation. Intriguingly, the overexpression of BCL2 promoted cell survival by maintaining cells in G0 phase, rather than causing them to proliferate as do other oncogenes [14], and mice harboring the BCL2 transgene showed lymphocyte accumulation without any propensity for tumorigenesis. However, when BCL2 was expressed with another oncogene $M Y C$, marked synergistic effects were observed, resulting in rapid lymphoma development from pre-B and B cells [15]. Together, these findings uncovered the unique role of BCL2 as a promoter of cell survival that enabled nascent neoplastic cells to survive for long enough to gain other oncogenic mutations, facilitating their eventual full malignant transformation. 


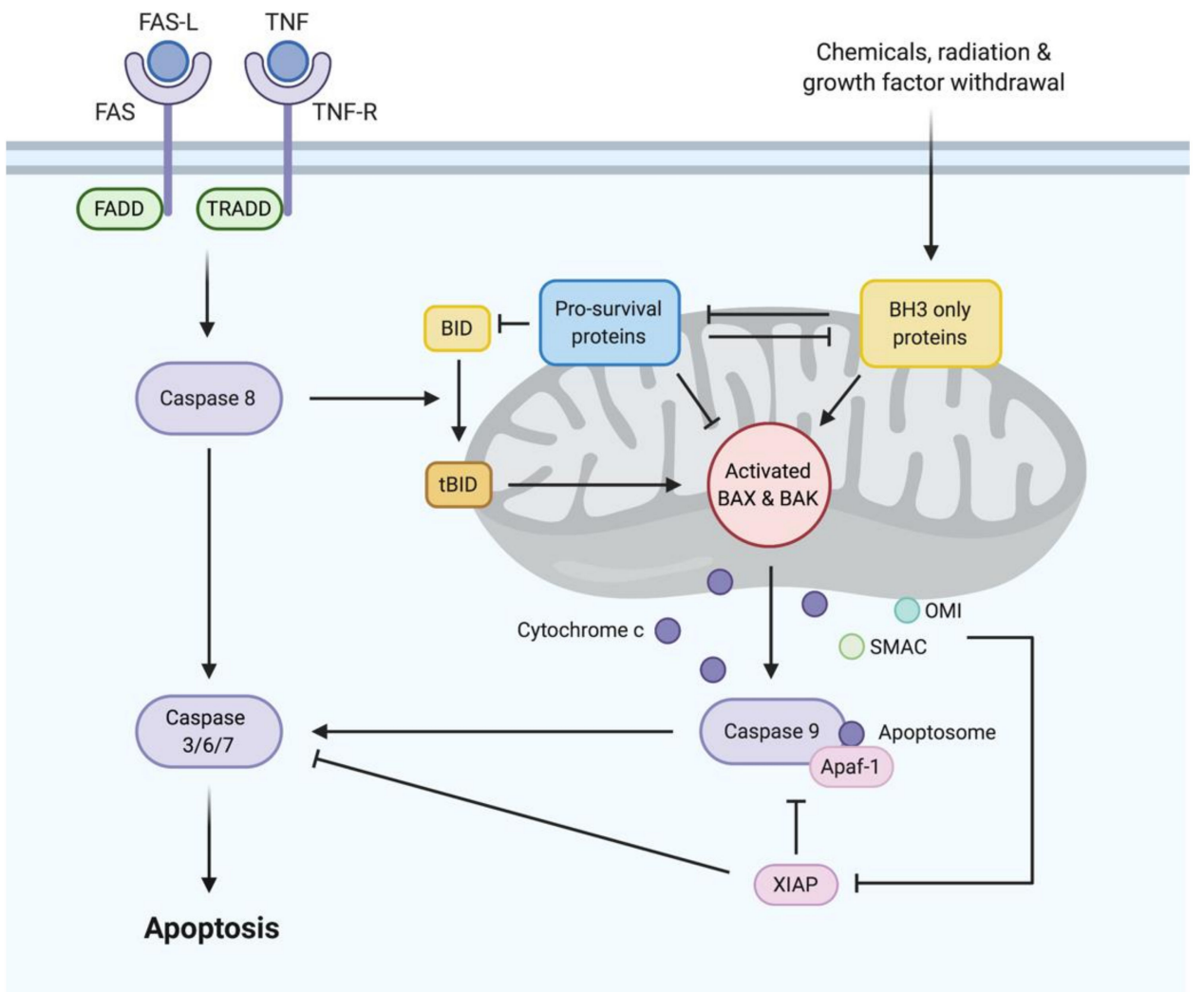

Figure 1. The extrinsic and intrinsic pathways to apoptosis. The extrinsic pathway is initiated when death receptor ligands (e.g., first apoptosis signal ligand [FAS-L], tumor necrosis factor (TNF)) bind to their cognate death receptors (e.g., first apoptosis signal [FAS], TNF receptor [TNFR]) on the plasma membrane, resulting in activation of caspase 8 via FAS-associated death domain protein (FADD) with or without TNFR-associated death domain protein (TRADD). The intrinsic pathway is triggered when diverse stress signals (e.g., DNA damage, growth factor deprivation) activate pro-apoptotic BH3-only proteins, which carry out their pro-apoptotic function by neutralizing pro-survival B-cell lymphoma 2 (BCL2) family proteins or, when these pro-survival proteins are saturated or absent, by directly activating BCL-associated X protein (BAX) and BCL2 homologous antagonist/killer (BAK), causing mitochondrial outer membrane permeabilization (MOMP). MOMP results in the release of a range of apoptogenic factors, including cytochrome c, from the intermembrane space of the mitochondria into the cytoplasm. In the cytoplasm, cytochrome $\mathrm{c}$ binds to apoptotic protease activating factor 1 (APAF1) to form the apoptosome, which mediates the activation of caspase 9 . The extrinsic and intrinsic pathways converge with initiator caspases (e.g., caspase 8, caspase 9) activating executioner caspases (e.g., caspase 3, caspase 7, caspase 6), which mediate cellular destruction.

Since the identification of BCL2, 16 additional BCL2 family proteins have been discovered, which share one or more of the BCL2 homology (BH) domains 1-4. Based on structure and function, members of the BCL2 family are divided into three distinct subgroups: pro-apoptotic effectors containing BH domains 1-3 (e.g., BCL2-associated X protein [BAX], BCL2 homologous antagonist/killer $[\mathrm{BAK}]$ ), pro-survival proteins containing all $\mathrm{BH}$ domains (e.g., BCL2, B-cell lymphoma extra large [BCLxL], BCLw, myeloid cell leukemia 1 [MCL1], BCL2-related protein A1), and pro-apoptotic BH3-only proteins containing only a single $\mathrm{BH} 3$ domain (e.g., BCL2-associated death promoter [BAD], BIM, BCL2 interacting killer [BIK], truncated $\mathrm{BH} 3$ interacting domain death agonist [t-BID], harakiri [HRK], BCL2 modifying factor [BMF], NOXA, p53 upregulated modulator of apoptosis [PUMA]). In the basal state, BAX mainly exists in the cytosol as an inactive monomer with its transmembrane domain folded into its hydrophobic groove [16], and BAK, while constitutively inserted into the outer mitochondrial membrane $[17,18]$, is likewise kept in an inactive monomeric state through its interaction with another 
outer mitochondrial protein called voltage-dependent anion-selective channel protein 2 (VDAC2) [19]. The activation of BAX induces the release of its transmembrane domain from its hydrophobic groove, facilitating its translocation to the outer mitochondrial membrane [16]. Similarly, the activation of BAK results in its liberation from VDAC2 [19]. Released BAX and BAK undergo further conformational changes to expose their hydrophobic groove and BH3 domain, which bind to each other across different molecules to facilitate the formation of BAX and BAK oligomers [8]. These oligomers are predicted to form macropores in the outer mitochondrial membrane, mediating MOMP and consigning the cell to apoptotic cell death. However, in the absence of apoptotic signals, BAX and BAK are sequestered by pro-survival proteins, which bind through their hydrophobic groove to the $\mathrm{BH} 3$ domains of their pro-apoptotic counterparts, inhibiting their activity [20]. Apoptotic stimuli result in the transcriptional and post-translational induction of pro-apoptotic BH3-only proteins, which carry out their pro-apoptotic function by either neutralizing the pro-survival proteins [21] or directly activating BAX and BAK [22-24]. BH3-only proteins bind to pro-survival proteins primarily through the insertion of four hydrophobic residues in its $\mathrm{BH} 3$ domain into the $\mathrm{P} 1$ to $\mathrm{P} 4$ pockets in the hydrophobic grooves of the pro-survival proteins. However, due to subtle differences in their BH3 domains and in the hydrophobic grooves of pro-survival proteins, some BH3-only proteins, such as BIM, PUMA, and t-BID, are able to bind with high affinity to all pro-survival proteins, whereas other BH3-only proteins, such as BAD and NOXA, only bind selectively to certain pro-survival proteins [21]. BAD predominantly binds to BCL2, BCLxL, and BCLw, and NOXA shows strong specificity toward MCL1 and A1, but not the other pro-survival proteins, making them less potent in inducing apoptosis.

\subsection{Dysregulation of Apoptosis in B-Cell Malignancies}

The intrinsic pathway of apoptosis is commonly perturbed in B-cell malignancies, including chronic lymphocytic leukemia (CLL), non-Hodgkin lymphomas (NHL) such as mantle cell lymphoma (MCL), FL and diffuse large B-cell lymphoma (DLBCL), and plasma cell dyscrasias such as multiple myeloma (MM) and Waldenström macroglobulinemia (WM). Several mechanisms have been described, including the overexpression of pro-survival proteins and loss of $\mathrm{BH}$-only protein function.

\subsubsection{Overexpression of Pro-Survival Proteins}

High BCL2 expression is almost universal in FL, CLL, MCL, and WM, but it occurs through diverse mechanisms. In FL, BCL2 overexpression is driven by the $t(14 ; 18)(q 32 ; q 21)$ translocation, which places the BCL2 gene on chromosome 18 under the control of the immunoglobulin heavy chain promoter on chromosome 14 [13]. In CLL, deletion of or mutations in the genetic loci for miR-15a and miR-16-1, which negatively regulate BCL2 expression, results in upregulation of BCL2 [25].

In addition to BCL2, MCL1 has been shown to be essential for the sustained expansion of MM [26] and MYC- or BCR-ABL1-driven pre-B or B-cell lymphomas [27,28]. Approximately 40\% of patients with MM carry a gain or amplification of 1q21, which is a chromosomal region that contains both the MCL1 and IL-6R genes [29], which is associated with inferior progression-free and overall survival [30]. In DLBCL, high MCL1 expression is seen predominantly in the activated B-cell (ABC) subtype and is driven by recurrent chromosomal gains or amplifications of the MCL1 locus in up to 26\% of cases [31].

Finally, elevated BCLxL expression is frequently seen in Burkitt lymphoma, DLBCL, and MM, due to either gene amplification or transcriptional and post-transcriptional regulation [32].

\subsubsection{Loss of BH3-Only Protein Function}

Homozygous BIM deletions have been described in some B-cell lymphomas, including MCL [33,34], and the epigenetic silencing of BIM has been implicated in glucocorticoid resistance in pediatric acute lymphoblastic leukemia (ALL) [35]. However, the dominant mechanism by which the activity of BH3-only proteins is dampened appears to be a loss of TP53 function through the deletion of chromosome 17p (del(17p)) and/or TP53 mutation, resulting in impairment of TP53-mediated induction of NOXA and PUMA in response to cellular stress, particularly DNA damage [36,37]. Accordingly, 
in CLL, MM, aggressive lymphomas, and B-lineage ALL, TP53 abnormalities have been associated with poor prognosis and resistance to DNA-damaging chemotherapy.

\subsection{BH3 Mimetics}

While cells overexpressing one or more pro-survival members of the BCL2 family have a clear survival advantage, paradoxically, they are also "primed for death", as inhibition of the upregulated pro-survival proteins would result in the release of large amounts of sequestered pro-apoptotic proteins, driving the cell toward apoptosis (Figure 2A). In other words, the cells become dependent on a specific pro-survival protein for their survival. This concept of "pro-survival addiction" sparked a search for small molecules that could mimic the function of BH3-only proteins in binding with high affinity to the hydrophobic groove of specific pro-survival proteins commonly overexpressed in B-cell malignancies, thereby restoring the capacity of cancer cells to undergo apoptosis. Despite initial doubts as to whether such a broad, hydrophobic protein-protein interface could be "drugged" at all, technological innovations, such as structure-activity relationship (SAR) by nuclear magnetic resonance (NMR) and state-of-the-art combinatorial chemistry, ultimately enabled the design of several potent and specific $\mathrm{BH} 3$ mimetics (Figure 2B).

A

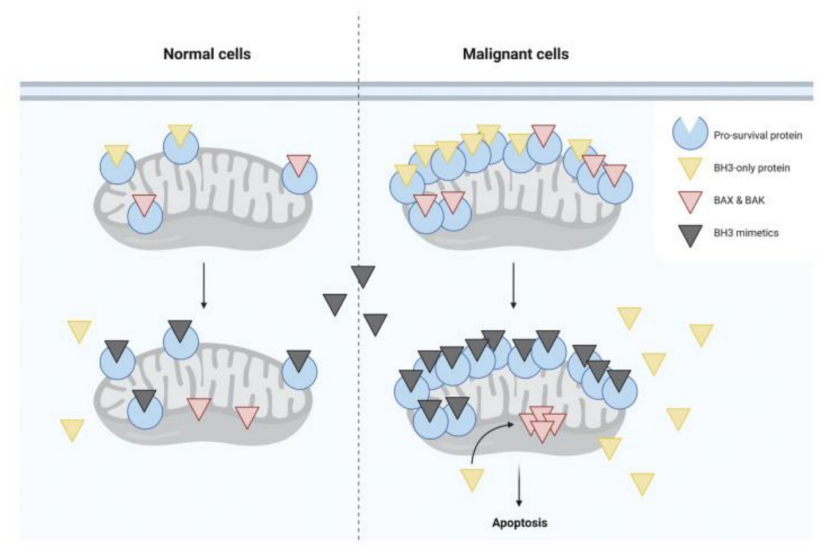

B

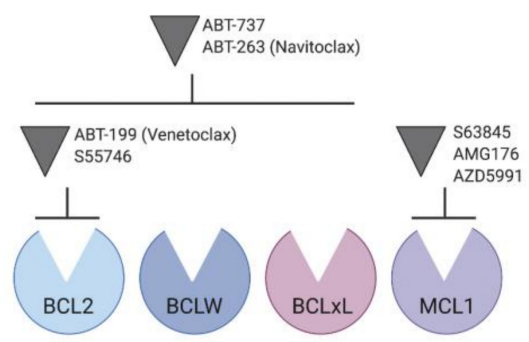

Figure 2. Mechanism of action of BH3 mimetics. (A) Pro-survival proteins (e.g., BCL2, B-cell lymphoma extra large [BCLxL], myeloid cell leukemia 1 [MCL1]), shown in blue, are commonly overexpressed in cancer cells, where they sequester high levels of pro-apoptotic proteins, including BH3-only proteins (e.g., BIM), shown in yellow, and pore-forming effector proteins (e.g., BAX, BAK), shown in red, through their BH3 motif to maintain cell survival. These cells are paradoxically "primed" for death, as inhibition of upregulated pro-survival proteins by $\mathrm{BH} 3$ mimetics would liberate large quantities of originally sequestered pro-apoptotic proteins, driving the cell toward apoptosis. (B) Different BH3 mimetics target different pro-survival proteins.

\section{BCL2 Inhibitors}

\subsection{ABT-737 and ABT-263 (Navitoclax)}

The first validated BH3 mimetic was reported in 2005 [38]. ABT-737 bound BCL2, BCLxL, and BCLw with high affinity, thereby mimicking the action of BH3-only protein BAD, demonstrating the sub-micromolar killing of primary cancer cells and cancer cell lines as well as anti-tumor activity in mouse models [38,39]. However, ABT-737 was not sufficiently orally bioavailable to take into clinical trials.

Navitoclax (ABT-263), an orally bioavailable ABT-737 analogue with the same target specificity and activity, was later described in 2008 and was successful in reaching clinical trials [40]. Among several tested B-cell malignancies, navitoclax was most potent against CLL, expressing high levels of 
BCL2 [40,41]. However, the development of navitoclax was ultimately curtailed by the dose-limiting thrombocytopenia induced by its on-target inhibition of BCLxL, which platelets rely on for their survival $[42,43]$.

\subsection{Venetoclax (ABT-199)}

In an effort to overcome this complication, drug-discovery scientists set out to create a BH3 mimetic that selectively targeted BCL2. The design of a BCL2-selective BH3 mimetic proved challenging due to the high degree of similarity in the BH3 domain of BCL2 and BCLxL. However, using reverse engineering, exploiting subtle differences between the binding interfaces of BCL2 and BCLxL, venetoclax (ABT-199/GDC-0199) was developed in 2013, which bound BCL2 with sub-nanomolar affinity, but interacted weakly with BCLxL and BCLw [44]. In sparing BCLxL, venetoclax had a limited effect on platelets but retained potent single-agent cytotoxic activity in a range of BCL2-dependent tumors, including CLL [44,45].

\subsubsection{Venetoclax in CLL}

Based on promising preclinical data, a phase 1 first-in-human trial of venetoclax (M12-175; NCT01328626) was conducted in 116 patients with relapsed and/or refractory (R/R) CLL (Table 1), including those harboring disease features associated with poor response to chemoimmunotherapy, such as fludarabine refractoriness, TP53 aberrations (e.g., del(17p), TP53 mutations) and unmutated immunoglobulin heavy chain variable region (IGHV) genes [46]. In two of the first three patients to be dosed with venetoclax, significant reductions in circulating tumor burden and palpable lymphadenopathy were seen within 8 hours and 24 hours, respectively [44]. Despite the majority of patients having received multiple lines of prior therapy, venetoclax proved to be active at all dose levels tested (150-1200 mg/day). The overall response rate (ORR) was $79 \%$, with $20 \%$ of patients achieving a complete response (CR) by International Workshop on CLL (iwCLL) criteria. Minimal residual disease (MRD) was evaluated in 17 of the 23 patients who had achieved a CR, and six (35\%) were found to be MRD negative, which is defined as less than one CLL cell detected per 10,000 leukocytes analyzed by multiparameter flow cytometry [47].

Remarkably, objective responses were seen in $79 \%$ of patients with fludarabine-resistant disease and $71 \%$ of patients with del(17p) CLL. These impressive results were consistent with the expected mechanism of action of venetoclax (Figure 2), which predicts that the activity of venetoclax should be independent of the presence of an intact TP53 pathway. Indeed, in vitro and in vivo sensitivity assays confirmed that response to venetoclax was not affected by del(17p), TP53 mutation, or loss of TP53 function [48]. In the clinical setting, the efficacy of venetoclax monotherapy in TP53-aberrant CLL was confirmed in a subsequent phase 2 trial (M13-982; NCT01889186) (Table 1), in which an ORR of 79.4\% was documented amongst 107 patients with R/R CLL who carried del(17p) and had received $\geq 1$ prior therapy [49]. Based on these results, venetoclax was granted breakthrough therapy designation by the United States Food and Drug Administration (FDA) in May 2015 and in April 2016 received approval for use in patients with CLL who have del(17p) and have received $\geq 1$ prior therapy. A separate phase 2 study evaluated venetoclax monotherapy in 127 patients with R/R CLL after B-cell receptor (BCR) inhibitor ibrutinib or idelalisib treatment (M14-032; NCT02141282) (Table 1) and observed ORRs of 65\% and $67 \%$ in the ibrutinib- and idelalisib-relapsed patients [50,51], delineating venetoclax as a viable therapeutic option after disease progression on BCR inhibitor therapy.

Although generally well-tolerated, venetoclax is not without toxicities. In a comprehensive safety analysis of venetoclax monotherapy using data from M12-175, M13-982, and M14-032, the most common adverse events of any grade were mild gastrointestinal symptoms and cytopenias [52]. In addition, tumor lysis syndrome (TLS) was identified early in the development of venetoclax as an important risk at drug initiation. Largely a consequence of the exquisite sensitivity of CLL cells to venetoclax, TLS was responsible for the death of two patients in early clinical trials [53]. Subsequent modifications 
to protocols, including dose escalation, TLS risk stratification, TLS prophylaxis, and close laboratory monitoring, have enabled TLS risk to be effectively mitigated [52].

Notwithstanding the impressive response rates obtained with single-agent venetoclax, preclinical data have strongly suggested that combining venetoclax with other agents may result in synergistic effects [44]. In a phase $1 \mathrm{~b}$ trial of venetoclax plus the anti-CD20 monoclonal antibody rituximab (VEN+R) in 49 patients with R/R CLL (M13-365; NCT01682616) (Table 1), an ORR of 86\% was achieved, including a CR in 51\% of patients [53]. Systematic evaluations of serial bone marrow (BM) samples demonstrated achievement of MRD negativity in $57 \%$ of all patients. Patients who achieved deep responses (CR or CR with incomplete marrow recovery [CRi] or MRD-negative PR) remained in ongoing remission for periods of up to 2 years after discontinuation of venetoclax therapy, demonstrating the feasibility of time-limited therapy for a subset of patients treated with VEN+R. Based on these results, VEN+R was granted breakthrough therapy designation by the FDA for use in R/R CLL in January 2016. The phase 3 MURANO trial (NCT02005471) compared the efficacy of VEN+R with standard chemoimmunotherapy, bendamustine plus rituximab (BR), in patients with R/R CLL (Table 1) [54]. After a median follow-up of 23.8 months, the rate of progression-free survival (PFS) was significantly higher in the VEN+R group than in the BR group $(84.9 \%$ vs. $36.3 \%$ ). Moreover, combination therapy with VEN+R achieved a higher MRD negativity rate than the standard BR regimen (83.5\% vs. $23.1 \%$ ) or any agent or combinations of agents previously evaluated in R/R CLL trials, suggesting that superior efficacy results can be attained by replacing chemotherapy with venetoclax than by adding other targeted agents to chemoimmunotherapy [55]. Not unexpectedly, $\mathrm{VEN}+\mathrm{R}$ was associated with a higher incidence of grade 3 or 4 neutropenia than BR (57.7\% vs. $38.8 \%)$, but TLS risk remained low at a rate of $3.1 \%$. The results of the MURANO trial resulted in the approval of venetoclax by the FDA for the treatment of patients with CLL or SLL irrespective of del(17p) status.

Combining venetoclax with the second-generation anti-CD20 antibody obinutuzumab (VEN+G) was shown to enhance cell death in CLL patient samples treated ex vivo [56], which is an observation that has since been recapitulated in the clinic. In the phase 3 CLL14 trial (NCT02242942) comparing the efficacy of VEN+G to chlorambucil-obinutuzumab in the front-line setting (Table 1), the proportion of patients with PFS at 24 months was significantly higher in the VEN+G group than in the chlorambucil-obinutuzumab group ( $88.2 \%$ vs. $64.1 \%$ ) [57]. Moreover, $49.5 \%$ of patients in the $\mathrm{VEN}+\mathrm{G}$ group achieved a $\mathrm{CR}$, which compares favorably to other therapies frequently used in this setting. The rate of MRD negativity was also higher in the VEN+G arm (75.5\% in PB, 56.9\% in BM) than in the chlorambucil-obinutuzumab arm (35.2\% in PB, 17.1\% in BM). Results from the CLL14 trial precipitated at last the approval of venetoclax as a front-line therapy in CLL or SLL in May 2019. The ongoing phase 2 HOVON 139/GIVE trial is currently investigating whether venetoclax-mediated TLS risk can be mitigated in the population unfit for fludarabine-containing chemoimmunotherapy by pre-induction with obinutuzumab and whether MRD-guided duration of venetoclax treatment is a feasible and effective approach [58]. In the reported interim safety analysis and preliminary data of the first 30 patients, pre-induction with obinutuzumab is well-tolerated and resulted in a downgrading of high TLS risk. A high proportion of patients achieved MRD negativity after combination therapy, providing preliminary evidence that this novel regimen utilizing venetoclax and obinutuzumab could result in a very high percentage of MRD negativity with an abrogation of TLS risk.

Aberrant BCR signaling plays an important role in the pathogenesis of CLL. Evidence suggests that the BCR of CLL cells is engaged by autoantigen, resulting in constitutive BCR activation in vivo [59-61]. Constitutive BCR signaling results in enhanced activity of kinases downstream of BCR, including phosphatidylinositol 3-kinase (PI3K) and Bruton tyrosine kinase (BTK), and drives not only the autonomous proliferation and survival of tumor cells, but also homing of tumor cells to protective niches in the BM and lymph nodes, providing the preclinical rationale for testing venetoclax in combination with PI3K and BTK inhibitors, which are known to mobilize CLL cells into the peripheral blood (PB) compartment. In BH3 profiling studies, treatment of CLL cells co-cultured with stroma with the PI3K- $\delta$ inhibitor idelalisib was shown to cause CLL cell de-adhesion, leading to increased apoptotic priming [62]. Similarly, the dual PI3K- $\delta$ and PI3K- $\gamma$ inhibitor duvelisib was shown in reverse 
phase protein arrays and immunoblots to increase BCL2 protein expression, increasing the sensitivity of ex vivo-cultured CLL cells obtained from duvelisib-treated patients to venetoclax [63]. Finally, the pharmacological profiling of residual circulating CLL cells from patients being treated with the BTK inhibitor ibrutinib revealed an exquisite dependence on BCL2 and sensitivity to venetoclax, which is likely related to increased mobilization of lymphocytes from lymph nodes and decreased levels of MCL1 and BCLxL following ibrutinib therapy [64]. Recently, the combination of venetoclax and ibrutinib (VEN+IBR) has been evaluated in patients with CLL in both the front-line and R/R settings. In an investigator-initiated phase 2 study of VEN+IBR in 80 older patients with previously untreated, high-risk CLL (Table 1), $88 \%$ of patients achieved CR or CRi after 12 cycles of the combination targeted therapy, and $61 \%$ attained MRD negativity [65]. The phase 2 CLARITY study combined venetoclax and ibrutinib in the treatment of 53 patients with R/R CLL [66]. After 12 months of VEN+IBR, an ORR of $89 \%$ was achieved, with $51 \%$ of patients attaining CR. MRD negativity was achieved in the PB of $53 \%$ and in the $\mathrm{BM}$ of $36 \%$. These results show the potent synergy between venetoclax and ibrutinib for the clearance of MRD, opening up the possibility of limited-duration VEN+IBR therapy for patients with CLL with a durable maintenance of remission.

The capacity of venetoclax-based combination therapy to enhance clinical efficacy has led to the emergence of multiple novel regimens attempting to combine venetoclax with up to two active agents while avoiding a concomitant increase in safety concerns. A phase $1 \mathrm{~b}$ study (NCT02427451) evaluated a fixed-duration regimen using sequentially administered obinutuzumab followed by VEN+IBR in 12 patients with R/R CLL (Table 1) [67]. The regimen was found to be safe and tolerable. An ORR of $92 \%$ was achieved, with $42 \%$ attaining a CR or CRi. In a subsequent phase 2 study of the triplet regimen in patients with either treatment-naïve or R/R CLL, a safety profile similar to the phase $1 \mathrm{~b}$ study was seen $[68,69]$. Objective responses were reported in all treatment-naïve patients to date, with 50\% achieving CR or CRi and 58\% achieving MRD negativity in both PB and BM [68]. The ORR of R/R patients at mid-therapy was $92 \%$, with $70 \%$ achieving MRD negativity in both PB and BM [69]. Furthermore, sequential treatment with two cycles of bendamustine, followed by induction and maintenance with VEN+G, has been investigated in the phase 2 CLL2-BAG trial (NCT02401503) (Table 1) [70]. The consecutive application of bendamustine and obinutuzumab combined with venetoclax caused no unexpected or cumulative toxicities. Objective responses were seen in $95 \%$ of patients at the end of induction, including all treatment-naïve patients and $90 \%$ of $R / R$ patients. Longer-term follow-up will likely clarify the durability of responses with these triplet regimens.

Table 1. Selected clinical trials of venetoclax in chronic lymphocytic leukemia (CLL).

\begin{tabular}{|c|c|c|c|c|c|}
\hline $\begin{array}{l}\text { ClinicalTrials.Gov } \\
\text { Identifier }\end{array}$ & Other Study ID Numbers & Intervention & Disease & $\begin{array}{c}\text { Study } \\
\text { Phase(s) }\end{array}$ & Publications \\
\hline \multicolumn{6}{|c|}{ VEN monotherapy } \\
\hline NCT01328626 & M12-175 & VEN & R/R CLL & 1 & [46] \\
\hline NCT01889186 & M13-982 & VEN & $\begin{array}{l}\text { R/R CLL with } \\
\text { del(17p) }\end{array}$ & 2 & {$[49,71]$} \\
\hline NCT02141282 & M14-032 & VEN & $\begin{array}{l}\text { R/R CLL after BCR } \\
\text { inhibitor therapy }\end{array}$ & 2 & {$[50,51]$} \\
\hline \multicolumn{6}{|c|}{ VEN combination therapy } \\
\hline NCT01682616 & M13-365 & VEN + R & R/R CLL/SLL & $1 \mathrm{~b}$ & [53] \\
\hline NCT02005471 & GO28667, MURANO & $\mathrm{VEN}+\mathrm{R}$ & R/R CLL & 3 & {$[54,72]$} \\
\hline NCT02242942 & BO25323, CLL14 & $\mathrm{VEN}+\mathrm{G}$ & CLL & 3 & [57] \\
\hline NCT02756897 & $2015-0860$ & VEN + IBR & R/R CLL & 2 & [65] \\
\hline NCT02427451 & OSU-14266, NCI-2015-00252 & $\mathrm{VEN}+\mathrm{IBR}+\mathrm{G}$ & R/R CLL & $1 b / 2$ & [67] \\
\hline NCT02401503 & CLL2-BAG, 2014-000580-40 & $\begin{array}{l}\text { Bendamustine } \\
+ \text { VEN + G }\end{array}$ & CLL & 2 & {$[70]$} \\
\hline
\end{tabular}




\subsubsection{Venetoclax in NHL}

Given that BCL2 was first discovered as a partner in the $t(14 ; 18)$ translocation that defines FL, venetoclax has also been extensively studied in the context of a range of NHLs. Early preclinical studies on venetoclax had shown potent cytotoxic activity in a subset of NHL cell lines, including not only FL, but also DLBCL and MCL, and these findings were replicated in xenograft models of DLBCL [44] and aggressive progenitor-cell lymphomas derived from bitransgenic MYC/BCL2 mice [73]. In the clinical setting, the initial phase 1 M12-175 trial of venetoclax monotherapy included a cohort of 106 patients with R/R NHL (Table 2) [74]. The trial found venetoclax to be well-tolerated in patients with R/R NHL and to have significant but varied single-agent activity amongst the different NHL subtypes [74]. The highest response rate was seen in MCL (ORR 75\%, CR 21\%, median PFS 14 months). Significant anti-tumor activity was also observed in FL (ORR 38\%, CR 14\%, median PFS 11 months) and DLBCL (ORR 18\%, CR 12\%, median PFS 1 month) [74].

The ideal combination partners for venetoclax in NHL remain unclear, although trials are underway to evaluate the safety and efficacy of combining venetoclax with chemotherapy, monoclonal antibodies, and BCR inhibitors. In the recent phase 2 AIM study, 24 patients with R/R or treatment-naïve MCL were treated with VEN+IBR combination therapy (Table 2) [75]. Dual targeting of BCL2 and BTK resulted in a $C R$ rate of $71 \%$. MRD negativity was documented in $67 \%$ of patients according to flow cytometry [75]. The phase 3 SYMPATICO study (NCT03112174) is currently comparing VEN+IBR combination therapy to that of ibrutinib and placebo (Table 2).

The phase 1b CAVALLI trial (NCT02055820) investigated the use of venetoclax in combination with R-CHOP or G-CHOP chemotherapy in 56 patients with NHL, the majority of whom had FL or DLBCL (Table 2) [76]. The ORR was $87.5 \%$ for the entire study population, and CR rates of $79.2 \%$ and $78.1 \%$ were achieved in the venetoclax plus R-CHOP and venetoclax plus G-CHOP arms, respectively [76]. These response rates compared favorably with historical rates from studies such as GOYA, GAUDI, and GALLIUM. The high CR rate of $87.5 \%$ in patients with double-expressor (BCL2+ MYC+) DLBCL was a particularly promising finding, and venetoclax plus R-CHOP is currently being evaluated in patients with newly diagnosed DLBCL in the phase 2 portion of the study [76].

Table 2. Selected clinical trials of venetoclax in non-Hodgkin lymphomas (NHLs).

\begin{tabular}{|c|c|c|c|c|c|}
\hline $\begin{array}{l}\text { Clinicaltrials.Gov } \\
\text { Identifier }\end{array}$ & Other Study ID Numbers & Intervention & Disease & $\begin{array}{l}\text { Study } \\
\text { Phase(s) }\end{array}$ & Publications \\
\hline \multicolumn{6}{|c|}{ VEN monotherapy } \\
\hline NCT01328626 & M12-175 & VEN & $\begin{array}{l}\text { R/R NHL (including MCL, } \\
\text { FL, DLBCL, RT-DLBCL, } \\
\text { WM, and MZL) }\end{array}$ & 1 & [74] \\
\hline \multicolumn{6}{|c|}{ VEN combination therapy } \\
\hline NCT02471391 & 14/148, AIM & VEN + IBR & MCL & 2 & [75] \\
\hline NCT03112174 & $\begin{array}{l}\text { PCYC-1143-CA, } \\
\text { SYMPATICO }\end{array}$ & VEN + IBR & MCL & 3 & N/A \\
\hline NCT02055820 & $\begin{array}{l}\text { GO27878, 2013-003749-40, } \\
\text { CAVALLI }\end{array}$ & $\begin{array}{c}\text { VEN + } \\
\text { R-/G-CHOP }\end{array}$ & $\begin{array}{l}\text { NHL (including FL and } \\
\text { DLBCL) }\end{array}$ & $1 b / 2$ & [76] \\
\hline
\end{tabular}

\subsubsection{Venetoclax in Plasma Cell Dyscrasias}

Multiple molecular subtypes of MM have been identified that demonstrate differential expression of pro-survival BCL2 family members [77], with survival dependencies contingent primarily on the distribution of BIM between BCL2/BCLxL and MCL1 [78]. Preclinical studies showed that, similar to ABT-737, venetoclax is particularly active against MM cell lines and patient samples with a $t(11 ; 14)$ translocation and high BCL2/MCL1 mRNA ratios [79]. The clinical efficacy of venetoclax in MM was first demonstrated in a phase 1 study of venetoclax monotherapy in $66 \mathrm{R} / \mathrm{R} \mathrm{MM}$ patients who had received a median of five prior therapies (NCT01794520) (Table 3) [80]. The trial reported an ORR of 
$21 \%$, with $15 \%$ of patients achieving at least a very good partial response ( $\geq$ VGPR). Consistent with in vitro studies, the majority of responses $(86 \%)$ in this phase 1 trial occurred in MM patients with $\mathrm{t}(11 ; 14)$. In this group, the ORR was $40 \%$, including $14 \% \mathrm{CR}$ and $13 \%$ VPGR, and the median PFS was 6.6 months.

The activity of single-agent venetoclax in MM is often compromised due to high MCL1 expression. The addition of the corticosteroid dexamethasone to venetoclax was shown to increase venetoclax efficiency in myeloma cell lines by upregulating the expression of BIM and shifting its binding toward BCL2 [81]. Furthermore, the proteasome inhibitor bortezomib was shown to induce apoptosis by stabilizing NOXA, which binds and neutralizes MCL1 [82-84]. Following studies in MM xenograft models where bortezomib was shown to enhance venetoclax efficiency, a phase 1b trial (NCT01794507) established the clinical efficacy of venetoclax in combination with bortezomib in the treatment of R/R MM (Table 3) [85]. Amongst 66 patients, an ORR of $67 \%$ was achieved, with $42 \%$ attaining $\geq$ VGPR. Based on these impressive results, the efficacy of venetoclax-bortezomib-dexamethasone was compared to that of placebo-bortezomib-dexamethasone in the phase 3 BELLINI trial in patients with R/R MM (NCT02755597) (Table 3) [86]. The addition of venetoclax to bortezomib and dexamethasone conferred a significant PFS benefit (22.9 months vs. 11.4 months). ORR and VPGR rates were also higher in the venetoclax arm compared to the placebo arm (ORR 84\% vs. 70\%, VPGR 61\% vs. 40\%). Despite promising PFS and response data, the overall survival findings were marred by an increased number of deaths in the venetoclax arm mainly due to treatment-emergent infections, prompting the FDA to place a partial clinical hold on all trials examining venetoclax in MM in March 2019.

Carfilzomib is a selective, second-generation proteasome inhibitor that demonstrated superior outcome compared to bortezomib for R/R MM patients in the phase 3 ENDEAVOR trial [87,88]. The safety and efficacy of venetoclax in combination with carfilzomib and dexamethasone (VenKd) are currently being assessed in the phase 1/2 M15-538 study (NCT02899052) (Table 3). Preliminary data suggest that VenKd is well-tolerated with promising clinical efficacy [89]. Ixazomib is the first oral proteasome inhibitor to be approved for R/R MM in combination with lenalidomide and dexamethasone [90]. The triple oral combination of venetoclax, ixazomib, and dexamethasone is currently being evaluated in a phase 1/2 study (NCT03399539) (Table 3).

In addition to proteasome inhibitors, venetoclax is also being combined with several monoclonal antibodies in the treatment of patients with MM. Daratumumab is a fully humanized monoclonal antibody targeting CD38, which has been approved for use in R/R MM. The phase 2 M15-654 trial (NCT03314181) is currently evaluating whether daratumumab could increase the anti-tumor activity of venetoclax and venetoclax-bortezomib combination therapy in R/R MM patients (Table 3). Early data demonstrates a tolerable safety profile with encouraging clinical efficacy, with objective responses seen in $92 \%$ of patients receiving venetoclax-daratumumab-dexamethasone combination therapy without bortezomib (VenDd) and $88 \%$ of patients receiving venetoclax-daratumumab-dexamethasone combination therapy with bortezomib (VenDVd) [91]. Interactions of MM cells with the BM microenvironment result in the dysregulation of several signaling pathways, including the Ras-Raf-MEK-ERK pathway [92]. Cobimetinib is a third-generation MEK inhibitor that has been evaluated in combination with the BRAF inhibitor vemurafenib in R/R extramedullary MM harboring the BRAF V600E mutation [93]. An ongoing phase 1b/2 study (NCT03312530) is assessing the safety and efficacy of cobimetinib monotherapy, cobimetinib plus venetoclax, and cobimetinib plus venetoclax plus an anti-PD-L1 monoclonal antibody atezolizumab in patients with R/R MM (Table 3).

In addition to MM, venetoclax is also being evaluated for use in patients with WM. In a phase 2 trial that included 31 patients with previously treated WM (NCT02677324), treatment with $800 \mathrm{mg}$ of daily venetoclax for a maximum of 2 years resulted in VGPR in six patients (19\%), PR in 19 (61\%), and a minor response in two (6\%) for an ORR of $87 \%$ and major response rate of $81 \%$ [94]. The 2-year PFS rate was $76 \%$. Grade 4 neutropenia occurred in five patients and grade 3 adverse events included neutropenia in 15 patients, anemia in four patients, and diarrhea in four. One instance of laboratory 
TLS occurred but no immunoglobulin M (IgM) flare, clinical TLS, or deaths were observed over a median follow-up of 18 months.

Table 3. Selected clinical trials of venetoclax in multiple myeloma (MM).

\begin{tabular}{|c|c|c|c|c|c|}
\hline $\begin{array}{l}\text { Clinicaltrials.Gov } \\
\text { Identifier }\end{array}$ & $\begin{array}{l}\text { Other Study ID } \\
\text { Numbers }\end{array}$ & Intervention & Disease & $\begin{array}{c}\text { Study } \\
\text { Phase(s) }\end{array}$ & Publications \\
\hline \multicolumn{6}{|c|}{ VEN monotherapy } \\
\hline NCT01794520 & $\begin{array}{c}\text { M13-367, } \\
\text { 2012-000589-38 }\end{array}$ & VEN & $\mathrm{R} / \mathrm{R} \mathrm{MM}$ & $1 / 2$ & {$[80]$} \\
\hline \multicolumn{6}{|c|}{ VEN combination therapy } \\
\hline NCT01794507 & $\begin{array}{c}\text { M12-901, } \\
\text { 2011-004626-10 }\end{array}$ & $\begin{array}{l}\text { VEN + bortezomib + } \\
\text { dexamethasone }\end{array}$ & $\mathrm{R} / \mathrm{R} \mathrm{MM}$ & 1 & [85] \\
\hline NCT02755597 & $\begin{array}{c}\text { M14-031, } \\
\text { 2015-004411-20 }\end{array}$ & $\begin{array}{l}\text { VEN + bortezomib + } \\
\text { dexamethasone }\end{array}$ & $\mathrm{R} / \mathrm{R} \mathrm{MM}$ & 3 & {$[86]$} \\
\hline NCT02899052 & M15-538 & $\begin{array}{l}\text { VEN + carfilzomib + } \\
\text { dexamethasone }\end{array}$ & $\mathrm{R} / \mathrm{R} \mathrm{MM}$ & 2 & [89] \\
\hline NCT03399539 & $\begin{array}{c}\text { MC168C, } \\
\text { NCI-2017-02456 }\end{array}$ & $\begin{array}{l}\text { VEN + ixazomib citrate + } \\
\text { dexamethasone }\end{array}$ & $\mathrm{R} / \mathrm{R} \mathrm{MM}$ & $1 / 2$ & $\mathrm{~N} / \mathrm{A}$ \\
\hline NCT03314181 & $\begin{array}{c}\text { M15-654, } \\
\text { 2017-002099-26 }\end{array}$ & $\begin{array}{c}\text { VEN + daratumumab + } \\
\text { dexamethasone }+/ \text { - bortezomib }\end{array}$ & $\mathrm{R} / \mathrm{R} \mathrm{MM}$ & 2 & [91] \\
\hline NCT03312530 & $\begin{array}{c}\text { BO39813, } \\
\text { 2017-000830-68 }\end{array}$ & $\begin{array}{l}\text { Cobimetinib + VEN +/- } \\
\text { atezolizumab }\end{array}$ & $\mathrm{R} / \mathrm{R} \mathrm{MM}$ & $1 b / 2$ & N/A \\
\hline
\end{tabular}

\subsection{Resistance to BCL2 Inhibitors}

Despite the impressive clinical efficacy of venetoclax across a range of B-cell malignancies, resistance to venetoclax occurs in a subset of patients and is an emerging therapeutic challenge. Venetoclax resistance can manifest either as the primary failure of certain tumor subtypes to respond to venetoclax or as acquired resistance driving disease progression on venetoclax therapy following an initial response [95].

\subsubsection{Primary Resistance to Venetoclax}

Early trials of single-agent venetoclax found that sensitivity to venetoclax varies greatly amongst different subtypes of B-cell malignancies. While the ORR of venetoclax monotherapy in CLL and MCL was high at 79\% and 75\% respectively, the ORR in FL, MM, and DLBCL was much lower at $38 \%, 21 \%$, and 18\%, respectively [46,74]. Preclinical studies have demonstrated a correlation between in vitro sensitivity to venetoclax and the relative expression of BCL2 to MCL1, BCLxL, or BIM in MCL [96], FL [97], and MM [79]. Whole-exome sequencing of tumor samples from the five MCL patients in the phase 2 AIM trial of VEN+IBR who failed to respond to the combination therapy revealed recurrent genomic abnormalities affecting the SWItch/Sucrose Non-Fermentable (SWI-SNF) chromatin-remodeling complex, including loss of chromosome 9p containing SMARCA2 in four out of the five patients, pathologic mutations or deletions in ARID2 in three patients, and mutations in the helicase domain of SMARCA4 in three patients [98]. The functional impairment of SWI-SNF through loss of SMARCA4 was shown to result in a dramatic reduction in chromatin accessibility at the locus of ATF3, a direct repressor of BCLxL transcription [99], leading to the downregulation of ATF3 and subsequent overexpression of BCLxL [98].

In addition to genomic abnormalities, soluble factors present in the tumor microenvironment, including CD40L and certain cytokines (e.g., IGF-1, BAFF, IL-6, IL-10), appear to be able to reduce the dependence of certain B-cell malignancies on BCL2 by upregulating one or more alternative pro-survival proteins [96,100-102]. Combining venetoclax with a BTK inhibitor, an anti-CD20 monoclonal antibody, or a dual SYK/JAK inhibitor has shown promise in being able to overcome microenvironment-mediated resistance in CLL and MCL [103,104]. 


\subsubsection{Acquired Resistance to Venetoclax}

Following a deep and durable response to venetoclax, a proportion of patients develop disease progression while on venetoclax therapy. The time to disease progression varies amongst different subtypes of B-cell malignancies. In patients with del(17p) CLL, approximately $50 \%$ relapse after 2 years on venetoclax monotherapy, highlighting the significant challenge that secondary resistance poses [71].

The mechanisms of acquired resistance to venetoclax are still the subject of ongoing research but are known to differ depending on tumor histology. In patients with CLL, the most common recurrent mechanism of venetoclax resistance identified to date is the acquisition of a point mutation in the $B C L 2$ gene, resulting in the substitution of a valine for glycine at position 101 of the BCL2 protein (G101V mutation) [105]. The emergence of the BCL2 G101V mutation during venetoclax treatment was detected initially in seven out of 15 patients enrolled in venetoclax trials with R/R CLL [105]. Interrogation of the structure of the mutant BCL2 protein revealed that the G101V mutation displaces the adjacent E152 residue into the base of the P2 hydrophobic pocket [106], disrupting the anchoring of venetoclax to BCL2 and causing an approximately 180-fold reduction in the binding affinity [105].

A subsequent study by Tausch and colleagues independently reported the emergence of the BCL2 G101V mutation and identified a second BCL2 D103Y mutation in one of the venetoclax-resistant patients [107]. Recently, multiple other novel BCL2 mutations acquired in parallel with BCL2 G101V mutation have been reported in patients with CLL progression, including D103E, D103V, V156D, R107_R110dup, A113G, and R129L [108]. However, the fact that these variants have only been detected mostly at low sub-clonal frequencies and in only a subset of patients suggests the presence of other acquired resistance mechanisms, which is a hypothesis that is further supported by the failure of two other whole-exome sequencing studies to detect any mutations in BCL2 in patients progressing on venetoclax $[109,110]$.

Unsurprisingly, the upregulation of alternative pro-survival proteins, in particular MCL1 and $B C L x L$, has been observed in CLL patients with acquired resistance to venetoclax. In one of the CLL patients with the BCL2 G101V mutation, increased BCLxL protein expression was detected in subclones without the BCL2 G101V mutation [105]. Moreover, amplification of a region on chromosome 1q23 containing MCL1 was recently identified in samples from CLL patients relapsing after venetoclax therapy [109]. Co-located with MCL1 on the amplified region of chromosome 1q23 is a positive regulatory subunit of AMP-activated protein kinase (AMPK) called PRKAB2, and there is evidence to suggest that the amplification of PRKAB2 may lead to enhanced activation of AMPK, resulting in increased oxidative phosphorylation that protects cells against the effect of venetoclax on the electron transport chain [109]. Other contributors of acquired resistance to venetoclax in CLL have been identified using whole-exome sequencing of samples from CLL patients relapsing early during venetoclax therapy, including homozygous deletions of $C D K N 2 A / B$ and BTG1 mutations [110]. These mechanisms are summarized in Figure 3.

Early in vitro studies using a murine MCL cell line observed the development of two BCL2 mutations, F101L and F101C, which are equivalent to F104L and F104C in humans [111]. In a model of MCL, resistance to venetoclax was observed to evolve from outgrowth of "persister" clones displaying a loss of 18q21 amplicons harboring BCL2 as well as adaptive super enhancer-driven transcriptional reprogramming [112]. However, to date, none of these mechanisms have been seen in patients with MCL treated with venetoclax. Recently, whole-exome sequencing of biopsy samples from seven patients with multiply relapsed MCL who received venetoclax-based therapies has revealed that unlike in CLL, BCL2 mutations are infrequent in venetoclax-resistant MCL, occurring in only one patient at progression; instead, the acquisition of non-BCL2 mutations, including alterations in TP53, SMARC4, CELSR3, CCND1 and KMT2D, may play a role in disease progression [113]. In FL, venetoclax resistance has been studied in $\mathrm{t}(14 ; 18)$ positive cell lines and increased phosphorylation of extracellular signal-regulated kinase 1/2 (ERK1/2) and decreased levels of BIM were seen in cell populations that survived venetoclax treatment [97]. However, the only putative mechanism of acquired venetoclax resistance reported in patients with FL to date is the acquisition of the BCL2 F104I 
mutation, which similar to the BCL2 G101V mutation results in an approximately 300-fold decrease in the affinity of venetoclax for BCL2 [114]. Further studies will likely help clarify the extent to which each mechanism contributes to disease progression on venetoclax and uncover novel determinants that will help to guide therapeutic selection.

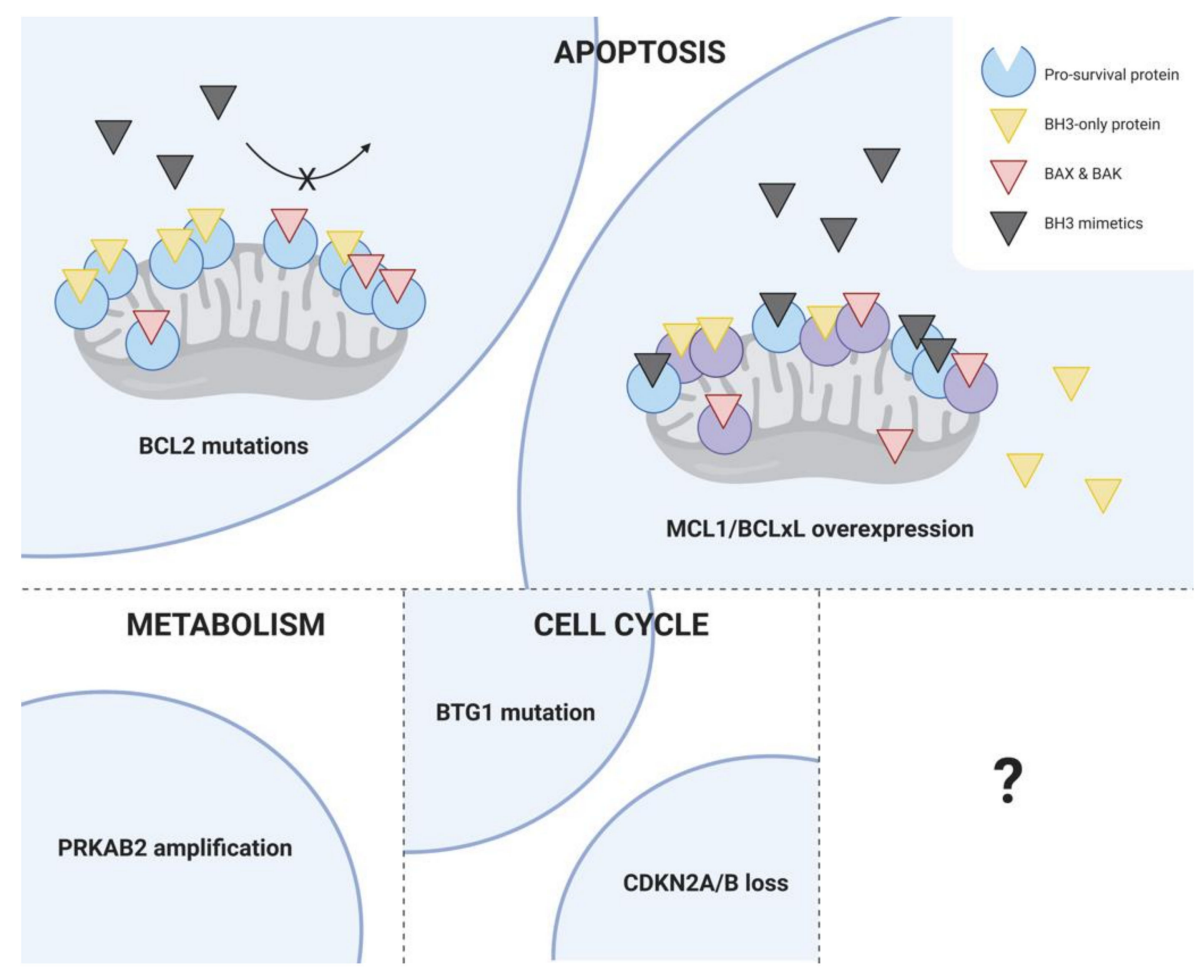

Figure 3. Mechanisms of acquired resistance to venetoclax in CLL. Although the factors contributing to disease progression on venetoclax are still the subject of ongoing research, available studies have identified a diverse range of mechanisms, which broadly target three cellular processes: apoptosis, metabolism, and the cell cycle. The most common recurrent mechanism of venetoclax resistance identified in CLL to date is the acquisition of the BCL2 G101V mutation, although other BCL2 mutations have also been detected (e.g., D103Y, D103E, D103V, V156D, R107_R110dup, A113G, R129L). Other mechanisms include the upregulation of alternative pro-survival proteins, particularly MCL1 and BCLxL, amplification of a positive regulatory subunit of AMPK called PRKAB2, leading to increased oxidative phosphorylation, homozygous deletions of $C D K N 2 A / B$, and BTG1 mutations.

\section{MCL1 Inhibitors}

Given the established role of MCL1 as a critical pro-survival factor in a range of hematologic malignancies, including MM, AML, and NHL [26,27,115-117], and a resistance factor to BH3 mimetics targeting BCL2 and BCLxL [118], there has been longstanding interest in designing potent and selective MCL1 inhibitors for therapeutic use. However, compared to BCL2 and BCLxL, MCL1 has proven to be more challenging to target, partly because its binding pocket is shallower and more rigid. Moreover, MCL1 has been shown in murine knockout models to play a critical role in the survival of a range of normal tissues, including cardiomyocytes [119,120], hematopoietic stem cells [121], developing and mature lymphocytes [122-126], and oocytes [127], leading to significant concerns around the potential toxicities associated with MCL1 inhibition. Despite this, progress on the development of selective MCL1 inhibitors has accelerated over recent years, and several compounds targeting MCL1 have now entered clinical trials, including AZD5991 [128], S64315/MIK665, AMG-176 [129], and AMG-397 (Table 4). 


\subsection{AZD5991}

AZD5991 is a rationally designed macrocyclic molecule with high selectivity and affinity for MCL1 [128]. in vivo, AZD5991 showed potent anti-tumor activity with complete tumor regression in several mouse and rat xenograft models of MM and AML after a single tolerated intravenous injection [128]. The activity of AZD5991 against MM and AML subcutaneous tumors was enhanced when the compound was administered in combination with bortezomib and venetoclax, respectively [128]. Based on these promising data, the clinical efficacy of AZD5991, administered intravenously every 21 days for nine cycles, is currently being evaluated in a phase 1 trial involving patients with $R / R$ hematologic malignancies (NCT03218683) (Table 4).

\section{2. $S 63845$ and S64315/MIK665}

S63845 is a highly potent MCL1 inhibitor that has exhibited impressive anti-tumor activity across a range of MCL1-dependent cancers, including MM and NHL [130]. Notably, in the context of MM, in contrast to the BCL2 inhibitor venetoclax [79], S63845 showed significant activity not only in MM cell lines carrying the $t(11 ; 14)$ translocation but also in those carrying genetic lesions associated with poor prognosis, including $\mathrm{t}(4 ; 14)$ and TP53 mutations, suggesting that MCL1 inhibitors may be effective in cases of MM refractory to standard chemotherapy [130]. Despite concerns regarding the important pro-survival role of MCL-1 in normal tissues, little toxicity was observed in mice treated with S63845 at doses capable of ablating mouse lymphoma cells [130]. Even though S63845 binds to human MCL-1 protein with six-fold higher affinity than it does to mouse MCL-1 protein, studies using a humanized Mcl-1 mouse model suggest that a therapeutic window could well be established and that drug-mediated inhibition has important phenotypic differences to genetic deletion of the Mcl-1 locus [131].

S64315/MIK665 is a compound closely related to S63845, for which minimal data have so far been disclosed. A phase 1 study is currently underway to assess the tolerability and preliminary efficacy of the related compound $\mathrm{S} 63415$ administered intravenously as a single agent in patients with MM (NCT02992483) (Table 4).

\section{3. $A M G-176$ and $A M G-397$}

Optimization of a series of spiromacrocyclic molecules using structure-based design and conformation restriction as guiding principles led to the discovery of a highly selective, orally bioavailable MCL1 inhibitor called AMG-176 [129]. The tool compound AM-8621, which was used to characterize the mechanism of action of AMG-176, has shown a promising effect in vitro. Among hematologic malignancies, MM, AML, and B-cell lymphoma demonstrated the greatest sensitivity to AM-8621 [129]. Given its superior pharmacokinetic properties over AM-8621, the efficacy of AMG-176 was further tested in murine models of MM and AML, and it was found to result in a significant reduction of tumor burden in a dose-dependent manner [129]. Synergistic effects could be achieved through the combination of AMG-176 with venetoclax in AML tumor models and in primary patient samples at a tolerated dose, highlighting the potential for dual MCL1 and BCL2 inhibition [129].

The safety and efficacy of AMG-176 are currently being evaluated both as monotherapy in patients with R/R MM and AML (NCT02675452) and in combination with venetoclax in patients with AML and NHL (NCT03797261) (Table 4). Although administered orally during in vivo studies, AMG-176 is being administered as an intravenous infusion in these clinical trials. The first oral MCL1 inhibitor to reach the clinic is a compound related to AMG-176 called AMG-397 [132]. The phase 1 trial assessing the safety, tolerability, pharmacokinetics, and efficacy of AMG-397 in patients with MM, NHL, and AML (NCT03465540) (Table 4) was placed on hold by the FDA in September 2019 after the discovery of a safety signal for cardiac toxicity, prompting Amgen, the drug manufacturer, to voluntarily halt the phase 1 studies of AMG-176 as a precaution, emphasizing the importance of clinical trials in 
establishing whether a wide enough therapeutic window can be found for MCL1 inhibitors to allow the use of this novel subclass of $\mathrm{BH} 3$ mimetics in patients.

Table 4. Clinical trials of MCL1 inhibitors.

\begin{tabular}{cccccc}
\hline $\begin{array}{c}\text { Clinicaltrials.Gov } \\
\text { Identifier }\end{array}$ & $\begin{array}{c}\text { Other Study ID } \\
\text { Numbers }\end{array}$ & Intervention & $\begin{array}{c}\text { Route of } \\
\text { Administration }\end{array}$ & Disease & $\begin{array}{c}\text { Study } \\
\text { Phase(s) }\end{array}$ \\
\hline NCT03218683 & D6910C00001 & AZD-5991 & IV & $\begin{array}{c}\text { R/R hematologic } \\
\text { malignancies }\end{array}$ & 1 \\
\hline NCT02992483 & $\begin{array}{c}\text { CMIK665 } 2101, \\
2016-003624-22\end{array}$ & MIK665 & IV & R/R MM, R/R NHL & 1 \\
\hline NCT02675452 & $\begin{array}{c}20150161, \\
2015-004777-32\end{array}$ & AMG-176 & IV & R/R MM & 1 \\
\hline NCT03465540 & 20170173 & AMG-397 & PO & R/R MM, R/R NHL & 1 \\
\hline
\end{tabular}

\section{BCLxL Inhibitors}

Despite early studies establishing the indispensable role of BCLxL in maintaining platelet viability [42], interest has remained in developing BH3 mimetics that selectively target BCLxL. Somatic amplification of BCLxL has previously been identified as a mechanism used by certain cancers to promote cell survival [133]. In addition, BCLxL has been strongly implicated as a chemoresistance factor [134], including to venetoclax, opening up the prospect of dual BCLxL and BCL2 inhibition to overcome venetoclax resistance. Finally, it is thought that the capacity of BCLxL inhibitors to suppress platelets could potentially be leveraged to treat myeloproliferative disorders characterized by malignant thrombocytosis. In recent years, several highly potent and selective BCLxL inhibitors have been described, including WEHI-539 [135], A-1155463 [136], and A-1331852 [137]. However, clinical progression of these agents has been challenging, largely due to their on-target effects on normal cells.

The first truly specific synthetic BCLxL inhibitor to be reported was WEHI-539 [135]. In contrast to ABT-737, WEHI-539 exhibited > 400-fold higher affinity for BCLxL than other pro-survival BCL2 family members [135]. As anticipated, WEHI-539 induced the rapid killing of isolated platelets in a caspase-dependent manner [135]. However, the utility of WEHI-539 as a tool compound was ultimately limited by unfavorable physicochemical properties that made in vivo dosing untenable [136]. Using NMR fragment screening, two BCLxL inhibitors were identified that were suitable for in vivo use: A-1155463 and its orally bioavailable relative A-1331852 [136,137]. A-1155463 demonstrated enhanced activity against BCLxL-dependent cell lines compared to WEHI-539, without possessing any of its pharmaceutical liabilities [136]. The intraperitoneal administration of A-1155364 produced reversible thrombocytopenia in non-tumor-bearing mice, and a modest reduction in tumor growth in small cell lung cancer xenografts [136]. Similarly, A-1331852, which has cellular activity 10-fold more potent than A-1155463, induced significant tumor regression as a single agent in ALL xenografts, and it potentiated the effects of docetaxel in subcutaneous xenograft models of solid tumors [137]. Despite promising in vivo activity, neither of these compounds have yet made it to the clinic.

\section{Conclusions and Future Directions}

BH3 mimetics are a novel class of therapeutics that is assuming an increasingly prominent role in the armamentarium against B-cell malignancies. So far, only the selective BCL2 inhibitor venetoclax has been approved for use in patients. The clinical success of venetoclax in treating CLL and AML has sparked enthusiasm to explore other indications for this agent and develop additional BH3 mimetics that can specifically target other pro-survival BCL2 family proteins. Several potent MCL1-specific inhibitors are currently being scrutinized in clinical trials for the treatment of MM and 
NHL, and selective BCLxL inhibitors have been designed showing significant anti-tumor activity both in vitro and in vivo.

Despite the promise that $\mathrm{BH} 3$ mimetics have shown, a number of key challenges remain. Firstly, only a relatively small number of B-cell malignancy subtypes have so far demonstrated clinically important sensitivity to $\mathrm{BH} 3$ mimetics as single agents. Current efforts to enhance the efficacy of BH3 mimetics in the clinic have predominantly focused on combining BH3 mimetics with other active agents. Clinical trials have so far confirmed the viability of combining venetoclax with conventional chemotherapeutics, monoclonal antibodies, kinase inhibitors, and proteasome inhibitors. Preclinical studies are elucidating the potential of combining histone deacetylase (HDAC) inhibitors and hypomethylating agents with venetoclax in MM and DLBCL [138,139]. Moreover, a high-throughput screen identified several new kinase inhibitors that may improve venetoclax therapy in R/R CLL in a personalized manner [102].

Another challenge for the further application of BH3 mimetics is on-target toxicity, especially for MCL1 and BCLXL inhibitors. Extensive preclinical tests have suggested that a therapeutic window could be established for MCL1 inhibitors, which has led to the entry of three MCL1 inhibitors into clinical trials. Data on the potential of these drugs are eagerly awaited. No BCLxL inhibitor has successfully entered clinical trials so far due to dose-limiting thrombocytopenia. Multiple innovative strategies are being explored to reduce the toxicity of $\mathrm{BH} 3$ mimetics, including conjugating them to antibodies directed specifically at cancer cells [140], encapsulating them in tumor-targeting nanoparticles [141], and converting them into proteolysis-targeting chimeras (PROTACs). Recently, a BCLxL-specific PROTAC created from navitoclax that targets BCLxL to the Von Hippel-Lindau (VHL) E3 ligase for degradation was shown to be able to selectively kill various BCLxL-dependent cancer cells with higher potency than venetoclax but significantly lower platelet toxicity due to minimal expression of VHL in platelets [142].

Finally, the mechanisms of drug resistance to BH3 mimetics appear complex and are yet to be fully delineated. A comprehensive understanding of determinants of venetoclax resistance will be necessary to inform optimal therapeutic strategies following venetoclax failure. The incorporation of correlative biological analyses linked to detailed genomic profiling of patient samples are therefore likely to become increasingly valuable for the identification of biomarkers to predict response in individual patients to this highly promising new class of therapeutics.

Author Contributions: V.S.L. and Z.-F.X. conceived the structure of the review, reviewed the literature, wrote the original draft of the manuscript, and constructed the tables and figures. D.C.S.H. and R.T. provided overall supervision and contributed to critical review of the manuscript. All authors have read and agreed to the published version of the manuscript.

Funding: Z.-F.X. is supported by a Scholarship from China Scholarship Council. D.C.S.H. is supported by Fellowship (1156024) and a Program Grant (1016701) from the Australian National Health and Medical Research Council (NHMRC) and a Specialized Center of Research [SCOR] grant (7015-18) from the Leukemia and Lymphoma Society. R.T. is supported by a Fellowship (5467-18) from the Leukemia and Lymphoma Society.

Acknowledgments: The authors thank all the patients, family members and staff who participated in the studies cited in this review.

Conflicts of Interest: D.C.S.H. and R.T. are employees of the Walter and Eliza Hall Institute of Medical Research, which receives milestone and royalty payments related to venetoclax. D.C.S.H. has received research funding from Genentech and Servier.

\section{References}

1. Kroemer, G.; Galluzzi, L.; Vandenabeele, P.; Abrams, J.; Alnemri, E.S.; Baehrecke, E.H.; Blagosklonny, M.V.; El-Deiry, W.S.; Golstein, P.; Green, D.R.; et al. Classification of cell death: Recommendations of the Nomenclature Committee on Cell Death 2009. Cell Death Diff. 2008, 16, 3-11. [CrossRef] [PubMed]

2. Kerr, J.F.; Wyllie, A.H.; Currie, A.R. Apoptosis: A basic biological phenomenon with wide-ranging implications in tissue kinetics. Br. J. Cancer 1972, 26, 239-257. [CrossRef] [PubMed] 
3. Honarpour, N.; Gilbert, S.L.; Lahn, B.T.; Wang, X.; Herz, J. Apaf-1 deficiency and neural tube closure defects are found in fog mice. Proc. Natl. Acad. Sci. USA 2001, 98, 9683-9687. [CrossRef] [PubMed]

4. Ke, F.F.S.; Vanyai, H.K.; Cowan, A.D.; Delbridge, A.R.D.; Whitehead, L.; Grabow, S.; Czabotar, P.E.; Voss, A.K.; Strasser, A. Embryogenesis and Adult Life in the Absence of Intrinsic Apoptosis Effectors BAX, BAK, and BOK. Cell 2018, 173, 1217-1230.e17. [CrossRef]

5. Knudson, C.M.; Tung, K.S.; Tourtellotte, W.G.; Brown, G.A.; Korsmeyer, S.J. Bax-deficient mice with lymphoid hyperplasia and male germ cell death. Science 1995, 270, 96-99. [CrossRef]

6. Eischen, C.M.; Roussel, M.F.; Korsmeyer, S.J.; Cleveland, J.L. Bax loss impairs Myc-induced apoptosis and circumvents the selection of p53 mutations during Myc-mediated lymphomagenesis. Mol. Cell Biol. 2001, 21, 7653-7662. [CrossRef] [PubMed]

7. Hanahan, D.; Weinberg, R.A. The hallmarks of cancer. Cell 2000, 100, 57-70. [CrossRef]

8. Dewson, G.; Kratina, T.; Sim, H.W.; Puthalakath, H.; Adams, J.M.; Colman, P.M.; Kluck, R.M. To Trigger Apoptosis, Bak Exposes Its BH3 Domain and Homodimerizes via BH3:Groove Interactions. Mol. Cell 2008, 30, 369-380. [CrossRef]

9. Saelens, X.; Festjens, N.; Walle, L.V.; Gurp, M.V.; Loo, G.V.; Vandenabeele, P. Toxic proteins released from mitochondria in cell death. Oncogene 2004, 23, 2861-2874. [CrossRef]

10. Green, D.R.; Kroemer, G. The pathophysiology of mitochondrial cell death. Science 2004, 305, 626-629. [CrossRef]

11. Bakhshi, A.; Jensen, J.P.; Goldman, P.; Wright, J.J.; McBride, O.W.; Epstein, A.L.; Korsmeyer, S.J. Cloning the chromosomal breakpoint of $\mathrm{t}(14 ; 18)$ human lymphomas: Clustering around JH on chromosome 14 and near a transcriptional unit on 18. Cell 1985, 41, 899-906. [CrossRef]

12. Tsujimoto, Y.; Cossman, J.; Jaffe, E.; Croce, C.M. Involvement of the bcl-2 gene in human follicular lymphoma. Science 1985, 228, 1440-1443. [CrossRef] [PubMed]

13. McDonnell, T.J.; Deane, N.; Platt, F.M.; Nunez, G.; Jaeger, U.; McKearn, J.P.; Korsmeyer, S.J. bcl-2-immunoglobulin transgenic mice demonstrate extended B cell survival and follicular lymphoproliferation. Cell 1989, 57, $79-88$. [CrossRef]

14. Vaux, D.L.; Cory, S.; Adams, J.M. Bcl-2 gene promotes haemopoietic cell survival and cooperates with c-myc to immortalize pre-B cells. Nature 1988, 335, 440-442. [CrossRef]

15. Strasser, A.; Harris, A.W.; Bath, M.L.; Cory, S. Novel primitive lymphoid tumours induced in transgenic mice by cooperation between myc and bcl-2. Nature 1990, 348, 331-333. [CrossRef]

16. Wolter, K.G.; Hsu, Y.T.; Smith, C.L.; Nechushtan, A.; Xi, X.G.; Youle, R.J. Movement of Bax from the cytosol to mitochondria during apoptosis. J. Cell Biol. 1997, 139, 1281-1292. [CrossRef]

17. Ferrer, P.E.; Frederick, P.; Gulbis, J.M.; Dewson, G.; Kluck, R.M. Translocation of a Bak C-terminus mutant from cytosol to mitochondria to mediate cytochrome $C$ release: Implications for Bak and Bax apoptotic function. PLoS ONE 2012, 7, e31510. [CrossRef]

18. Griffiths, G.J.; Dubrez, L.; Morgan, C.P.; Jones, N.A.; Whitehouse, J.; Corfe, B.M.; Dive, C.; Hickman, J.A. Cell damage-induced conformational changes of the pro-apoptotic protein Bak in vivo precede the onset of apoptosis. J. Cell Biol. 1999, 144, 903-914. [CrossRef]

19. Cheng, E.H.; Sheiko, T.V.; Fisher, J.K.; Craigen, W.J.; Korsmeyer, S.J. VDAC2 inhibits BAK activation and mitochondrial apoptosis. Science 2003, 301, 513-517. [CrossRef]

20. Cheng, E.H.Y.A.; Wei, M.C.; Weiler, S.; Flavell, R.A.; Mak, T.W.; Lindsten, T.; Korsmeyer, S.J. BCL-2, BCL-XL Sequester BH3 Domain-Only Molecules Preventing BAX- and BAK-Mediated Mitochondrial Apoptosis. Mol. Cell 2001, 8, 705-711. [CrossRef]

21. Chen, L.; Willis, S.N.; Wei, A.; Smith, B.J.; Fletcher, J.I.; Hinds, M.G.; Colman, P.M.; Day, C.L.; Adams, J.M.; Huang, D.C.S. Differential Targeting of Prosurvival Bcl-2 Proteins by Their BH3-Only Ligands Allows Complementary Apoptotic Function. Mol. Cell 2005, 17, 393-403. [CrossRef] [PubMed]

22. Zong, W.X. BH3-only proteins that bind pro-survival Bcl-2 family members fail to induce apoptosis in the absence of Bax and Bak. Genes Dev. 2001, 15, 1481-1486. [CrossRef] [PubMed]

23. Kuwana, T.; Bouchier-Hayes, L.; Chipuk, J.E.; Bonzon, C.; Sullivan, B.A.; Green, D.R.; Newmeyer, D.D. $\mathrm{BH} 3$ domains of BH3-only proteins differentially regulate Bax-mediated mitochondrial membrane permeabilization both directly and indirectly. Mol. Cell 2005, 17, 525-535. [CrossRef] [PubMed] 
24. Cartron, P.F.; Gallenne, T.; Bougras, G.; Gautier, F.; Manero, F.; Vusio, P.; Meflah, K.; Vallette, F.M.; Juin, P. The first alpha helix of Bax plays a necessary role in its ligand-induced activation by the BH3-only proteins Bid and PUMA. Mol. Cell 2004, 16, 807-818. [CrossRef] [PubMed]

25. Cimmino, A.; Calin, G.A.; Fabbri, M.; Iorio, M.V.; Ferracin, M.; Shimizu, M.; Wojcik, S.E.; Aqeilan, R.I.; Zupo, S.; Dono, M.; et al. miR-15 and miR-16 induce apoptosis by targeting BCL2. Proc. Natl. Acad. Sci. USA 2005, 102, 13944-13949. [CrossRef]

26. Gong, J.N.; Khong, T.; Segal, D.; Yao, Y.; Riffkin, C.D.; Garnier, J.M.; Khaw, S.L.; Lessene, G.; Spencer, A.; Herold, M.J.; et al. Hierarchy for targeting prosurvival BCL2 family proteins in multiple myeloma: Pivotal role of MCL1. Blood 2016, 128, 1834-1844. [CrossRef]

27. Kelly, G.L.; Grabow, S.; Glaser, S.P.; Fitzsimmons, L.; Aubrey, B.J.; Okamoto, T.; Valente, L.J.; Robati, M.; Tai, L.; Fairlie, W.D.; et al. Targeting of MCL-1 kills MYC-driven mouse and human lymphomas even when they bear mutations in p53. Genes Dev. 2014, 28, 58-70. [CrossRef]

28. Koss, B.; Morrison, J.; Perciavalle, R.M.; Singh, H.; Rehg, J.E.; Williams, R.T.; Opferman, J.T. Requirement for antiapoptotic MCL-1 in the survival of BCR-ABL B-lineage acute lymphoblastic leukemia. Blood 2013, 122, 1587-1598. [CrossRef]

29. Slomp, A.; Peperzak, V. Role and Regulation of Pro-survival BCL-2 Proteins in Multiple Myeloma. Front. Oncol. 2018, 8, 533. [CrossRef]

30. Shah, V.; Sherborne, A.L.; Walker, B.A.; Johnson, D.C.; Boyle, E.M.; Ellis, S.; Begum, D.B.; Proszek, P.Z.; Jones, J.R.; Pawlyn, C.; et al. Prediction of outcome in newly diagnosed myeloma: A meta-analysis of the molecular profiles of 1905 trial patients. Leukemia 2017, 32, 102-110. [CrossRef]

31. Wenzel, S.S.; Grau, M.; Mavis, C.; Hailfinger, S.; Wolf, A.; Madle, H.; Deeb, G.; Dörken, B.; Thome, M.; Lenz, P.; et al. MCL1 is deregulated in subgroups of diffuse large B-cell lymphoma. Leukemia 2012, 27, 1381-1390. [CrossRef] [PubMed]

32. Xerri, L.; Parc, P.; Brousset, P.; Schlaifer, D.; Hassoun, J.; Reed, J.C.; Krajewski, S.; Birnbaum, D. Predominant expression of the long isoform of Bcl-x (Bcl-xL) in human lymphomas. Br. J. Haematol. 1996, 92, 900-906. [CrossRef] [PubMed]

33. Tagawa, H.; Karnan, S.; Suzuki, R.; Matsuo, K.; Zhang, X.; Ota, A.; Morishima, Y.; Nakamura, S.; Seto, M. Genome-wide array-based CGH for mantle cell lymphoma: Identification of homozygous deletions of the proapoptotic gene BIM. Oncogene 2005, 24, 1348-1358. [CrossRef]

34. Mestre-Escorihuela, C.; Rubio-Moscardo, F.; Richter, J.A.; Siebert, R.; Climent, J.; Fresquet, V.; Beltran, E.; Agirre, X.; Marugan, I.; Marín, M.; et al. Homozygous deletions localize novel tumor suppressor genes in B-cell lymphomas. Blood 2006, 109, 271-280. [CrossRef]

35. Bachmann, P.S.; Piazza, R.G.; Janes, M.E.; Wong, N.C.; Davies, C.; Mogavero, A.; Bhadri, V.A.; Szymanska, B.; Geninson, G.; Magistroni, V.; et al. Epigenetic silencing of BIM in glucocorticoid poor-responsive pediatric acute lymphoblastic leukemia, and its reversal by histone deacetylase inhibition. Blood 2010, 116, 3013-3022. [CrossRef]

36. Oda, E.; Ohki, R.; Murasawa, H.; Nemoto, J.; Shibue, T.; Yamashita, T.; Tokino, T.; Taniguchi, T.; Tanaka, N. Noxa, a BH3-only member of the Bcl-2 family and candidate mediator of p53-induced apoptosis. Science 2000, 288, 1053-1058. [CrossRef]

37. Zenz, T.; Eichhorst, B.; Busch, R.; Denzel, T.; Häbe, S.; Winkler, D.; Bühler, A.; Edelmann, J.; Bergmann, M.; Hopfinger, G.; et al. TP53 Mutation and Survival in Chronic Lymphocytic Leukemia. J. Clin. Oncol. 2010, 28, 4473-4479. [CrossRef]

38. Oltersdorf, T.; Elmore, S.W.; Shoemaker, A.R.; Armstrong, R.C.; Augeri, D.J.; Belli, B.A.; Bruncko, M.; Deckwerth, T.L.; Dinges, J.; Hajduk, P.J.; et al. An inhibitor of Bcl-2 family proteins induces regression of solid tumours. Nature 2005, 435, 677-681. [CrossRef] [PubMed]

39. Del Gaizo Moore, V.; Brown, J.R.; Certo, M.; Love, T.M.; Novina, C.D.; Letai, A. Chronic lymphocytic leukemia requires BCL2 to sequester prodeath BIM, explaining sensitivity to BCL2 antagonist ABT-737. J. Clin. Investig. 2007, 117, 112-121. [CrossRef]

40. Tse, C.; Shoemaker, A.R.; Adickes, J.; Anderson, M.G.; Chen, J.; Jin, S.; Johnson, E.F.; Marsh, K.C.; Mitten, M.J.; Nimmer, P.; et al. ABT-263: A Potent and Orally Bioavailable Bcl-2 Family Inhibitor. Cancer Res. 2008, 68, 3421-3428. [CrossRef] [PubMed]

41. Mason, K.D.; Khaw, S.L.; Rayeroux, K.C.; Chew, E.; Lee, E.F.; Fairlie, W.D.; Grigg, A.P.; Seymour, J.F.; Szer, J.; Huang, D.C.; et al. The BH3 mimetic compound, ABT-737, synergizes with a range of cytotoxic chemotherapy agents in chronic lymphocytic leukemia. Leukemia 2009, 23, 2034-2041. [CrossRef] [PubMed] 
42. Mason, K.D.; Carpinelli, M.R.; Fletcher, J.I.; Collinge, J.E.; Hilton, A.A.; Ellis, S.; Kelly, P.N.; Ekert, P.G.; Metcalf, D.; Roberts, A.W.; et al. Programmed anuclear cell death delimits platelet life span. Cell 2007, 128, 1173-1186. [CrossRef] [PubMed]

43. Wilson, W.H.; O'Connor, O.A.; Czuczman, M.S.; LaCasce, A.S.; Gerecitano, J.F.; Leonard, J.P.; Tulpule, A.; Dunleavy, K.; Xiong, H.; Chiu, Y.L.; et al. Navitoclax, a targeted high-affinity inhibitor of BCL-2, in lymphoid malignancies: A phase 1 dose-escalation study of safety, pharmacokinetics, pharmacodynamics, and antitumour activity. Lancet Oncol. 2010, 11, 1149-1159. [CrossRef]

44. Souers, A.J.; Leverson, J.D.; Boghaert, E.R.; Ackler, S.L.; Catron, N.D.; Chen, J.; Dayton, B.D.; Ding, H.; Enschede, S.H.; Fairbrother, W.J.; et al. ABT-199, a potent and selective BCL-2 inhibitor, achieves antitumor activity while sparing platelets. Nat. Med. 2013, 19, 202-208. [CrossRef] [PubMed]

45. Vogler, M.; Dinsdale, D.; Dyer, M.J.; Cohen, G.M. ABT-199 selectively inhibits BCL2 but not BCL2L1 and efficiently induces apoptosis of chronic lymphocytic leukaemic cells but not platelets. Br. J. Haematol. 2013, 163, 139-142. [CrossRef]

46. Roberts, A.W.; Davids, M.S.; Pagel, J.M.; Kahl, B.S.; Puvvada, S.D.; Gerecitano, J.F.; Kipps, T.J.; Anderson, M.A.; Brown, J.R.; Gressick, L.; et al. Targeting BCL2 with Venetoclax in Relapsed Chronic Lymphocytic Leukemia. N. Engl. J. Med. 2016, 374, 311-322. [CrossRef]

47. Rawstron, A.C.; Bottcher, S.; Letestu, R.; Villamor, N.; Fazi, C.; Kartsios, H.; de Tute, R.M.; Shingles, J.; Ritgen, M.; Moreno, C.; et al. Improving efficiency and sensitivity: European Research Initiative in CLL (ERIC) update on the international harmonised approach for flow cytometric residual disease monitoring in CLL. Leukemia 2013, 27, 142-149. [CrossRef]

48. Anderson, M.A.; Deng, J.; Seymour, J.F.; Tam, C.; Kim, S.Y.; Fein, J.; Yu, L.; Brown, J.R.; Westerman, D.; $\mathrm{Si}$, E.G.; et al. The BCL2 selective inhibitor venetoclax induces rapid onset apoptosis of CLL cells in patients via a TP53-independent mechanism. Blood 2016, 127, 3215-3224. [CrossRef]

49. Stilgenbauer, S.; Eichhorst, B.; Schetelig, J.; Coutre, S.; Seymour, J.F.; Munir, T.; Puvvada, S.D.; Wendtner, C.-M.; Roberts, A.W.; Jurczak, W.; et al. Venetoclax in relapsed or refractory chronic lymphocytic leukaemia with 17p deletion: A multicentre, open-label, phase 2 study. Lancet Oncol. 2016, 17, 768-778. [CrossRef]

50. Jones, J.A.; Mato, A.R.; Wierda, W.G.; Davids, M.S.; Choi, M.; Cheson, B.D.; Furman, R.R.; Lamanna, N.; Barr, P.M.; Zhou, L.; et al. Venetoclax for chronic lymphocytic leukaemia progressing after ibrutinib: An interim analysis of a multicentre, open-label, phase 2 trial. Lancet Oncol. 2018, 19, 65-75. [CrossRef]

51. Coutre, S.; Choi, M.; Furman, R.R.; Eradat, H.; Heffner, L.; Jones, J.A.; Chyla, B.; Zhou, L.; Agarwal, S.; Waskiewicz, T.; et al. Venetoclax for patients with chronic lymphocytic leukemia who progressed during or after idelalisib therapy. Blood 2018, 131, 1704-1711. [CrossRef] [PubMed]

52. Davids, M.S.; Hallek, M.; Wierda, W.; Roberts, A.W.; Stilgenbauer, S.; Jones, J.A.; Gerecitano, J.F.; Kim, S.Y.; Potluri, J.; Busman, T.; et al. Comprehensive Safety Analysis of Venetoclax Monotherapy for Patients with Relapsed/Refractory Chronic Lymphocytic Leukemia. Clin. Cancer Res. 2018, 24, 4371-4379. [CrossRef] [PubMed]

53. Seymour, J.F.; Ma, S.; Brander, D.M.; Choi, M.Y.; Barrientos, J.; Davids, M.S.; Anderson, M.A.; Beaven, A.W.; Rosen, S.T.; Tam, C.S.; et al. Venetoclax plus rituximab in relapsed or refractory chronic lymphocytic leukaemia: A phase 1b study. Lancet Oncol. 2017, 18, 230-240. [CrossRef]

54. Seymour, J.F.; Kipps, T.J.; Eichhorst, B.; Hillmen, P.; D’Rozario, J.; Assouline, S.; Owen, C.; Gerecitano, J.; Robak, T.; De la Serna, J.; et al. Venetoclax-Rituximab in Relapsed or Refractory Chronic Lymphocytic Leukemia. N. Engl. J. Med. 2018, 378, 1107-1120. [CrossRef]

55. Chanan-Khan, A.; Cramer, P.; Demirkan, F.; Fraser, G.; Silva, R.S.; Grosicki, S.; Pristupa, A.; Janssens, A.; Mayer, J.; Bartlett, N.L.; et al. Ibrutinib combined with bendamustine and rituximab compared with placebo, bendamustine, and rituximab for previously treated chronic lymphocytic leukaemia or small lymphocytic lymphoma (HELIOS): A randomised, double-blind, phase 3 study. Lancet Oncol. 2016, 17, 200-211. [CrossRef]

56. Sampath, D.; Herter, S.; Herting, F.; Ingalla, E.; Nannini, M.; Bacac, M.; Fairbrother, W.J.; Klein, C. Combination of the glycoengineered Type II CD20 antibody obinutuzumab (GA101) and The novel Bcl-2 selective Inhibitor GDC-0199 Results in superior In Vitro and In Vivo Anti-tumor activity in models Of B-Cell Malignancies. Blood 2013, 122, 4412. [CrossRef]

57. Fischer, K.; Al-Sawaf, O.; Bahlo, J.; Fink, A.M.; Tandon, M.; Dixon, M.; Robrecht, S.; Warburton, S.; Humphrey, K.; Samoylova, O.; et al. Venetoclax and Obinutuzumab in Patients with CLL and Coexisting Conditions. N. Engl. J. Med. 2019, 380, 2225-2236. [CrossRef] 
58. Kater, A.P.; Kersting, S.; van Norden, Y.; Dubois, J.; Dobber, J.A.; Mellink, C.H.; Evers, L.M.; Croon-de Boer, F.; Schreurs, J.; van der Spek, E.; et al. Obinutuzumab pretreatment abrogates tumor lysis risk while maintaining undetectable MRD for venetoclax + obinutuzumab in CLL. Blood Adv. 2018, 2, 3566-3571. [CrossRef]

59. Herishanu, Y.; Pérez-Galán, P.; Liu, D.; Biancotto, A.; Pittaluga, S.; Vire, B.; Gibellini, F.; Njuguna, N.; Lee, E.; Stennett, L.; et al. The lymph node microenvironment promotes B-cell receptor signaling, NF- $\mathrm{B}$ activation, and tumor proliferation in chronic lymphocytic leukemia. Blood 2011, 117, 563-574. [CrossRef]

60. Mockridge, C.I.; Potter, K.N.; Wheatley, I.; Neville, L.A.; Packham, G.; Stevenson, F.K. Reversible anergy of sIgM-mediated signaling in the two subsets of CLL defined by VH-gene mutational status. Blood 2007, 109, 4424-4431. [CrossRef]

61. Duhren-von Minden, M.; Ubelhart, R.; Schneider, D.; Wossning, T.; Bach, M.P.; Buchner, M.; Hofmann, D.; Surova, E.; Follo, M.; Kohler, F.; et al. Chronic lymphocytic leukaemia is driven by antigen-independent cell-autonomous signalling. Nature 2012, 489, 309-312. [CrossRef] [PubMed]

62. Davids, M.S.; Deng, J.; Wiestner, A.; Lannutti, B.J.; Wang, L.; Wu, C.J.; Wilson, W.H.; Brown, J.R.; Letai, A. Decreased mitochondrial apoptotic priming underlies stroma-mediated treatment resistance in chronic lymphocytic leukemia. Blood 2012, 120, 3501-3509. [CrossRef] [PubMed]

63. Patel, V.M.; Balakrishnan, K.; Douglas, M.; Tibbitts, T.; Xu, E.Y.; Kutok, J.L.; Ayers, M.; Sarkar, A.; Guerrieri, R.; Wierda, W.G.; et al. Duvelisib treatment is associated with altered expression of apoptotic regulators that helps in sensitization of chronic lymphocytic leukemia cells to venetoclax (ABT-199). Leukemia 2017, 31, 1872-1881. [CrossRef] [PubMed]

64. Cervantes-Gomez, F.; Lamothe, B.; Woyach, J.A.; Wierda, W.G.; Keating, M.J.; Balakrishnan, K.; Gandhi, V. Pharmacological and Protein Profiling Suggests Venetoclax (ABT-199) as Optimal Partner with Ibrutinib in Chronic Lymphocytic Leukemia. Clin. Cancer Res. 2015, 21, 3705-3715. [CrossRef]

65. Jain, N.; Keating, M.; Thompson, P.; Ferrajoli, A.; Burger, J.; Borthakur, G.; Takahashi, K.; Estrov, Z.; Fowler, N.; Kadia, T.; et al. Ibrutinib and Venetoclax for First-Line Treatment of CLL. N. Engl. J. Med. 2019, 380, 2095-2103. [CrossRef]

66. Hillmen, P.; Rawstron, A.C.; Brock, K.; Munoz-Vicente, S.; Yates, F.J.; Bishop, R.; Boucher, R.; MacDonald, D.; Fegan, C.; McCaig, A.; et al. Ibrutinib Plus Venetoclax in Relapsed/Refractory Chronic Lymphocytic Leukemia: The CLARITY Study. J. Clin. Oncol. 2019, 37, 2722-2729. [CrossRef]

67. Rogers, K.A.; Huang, Y.; Ruppert, A.S.; Awan, F.T.; Heerema, N.A.; Hoffman, C.; Lozanski, G.; Maddocks, K.J.; Moran, M.E.; Reid, M.A.; et al. Phase $1 b$ study of obinutuzumab, ibrutinib, and venetoclax in relapsed and refractory chronic lymphocytic leukemia. Blood 2018, 132, 1568-1572. [CrossRef]

68. Rogers, K.A.; Huang, Y.; Stark, A.; Awan, F.T.; Maddocks, K.J.; Woyach, J.A.; Whitlow, T.; Byrd, J.C.; Jones, J.A. Initial Results of the Phase 2 Treatment Naive Cohort in a Phase 1b/2 Study of Obinutuzumab, Ibrutinib, and Venetoclax in Chronic Lymphocytic Leukemia. Blood 2017, 130 (Suppl. 1), 431.

69. Rogers, K.A.; Huang, Y.; Ruppert, A.S.; Awan, F.T.; Hoffman, C.; Maddocks, K.J.; Reid, M.; Woyach, J.A.; Whitlow, T.; Jones, J.A.; et al. Phase 2 Study of Combination Obinutuzumab, Ibrutinib, and Venetoclax in Treatment-Naive and Relapsed/Refractory Chronic Lymphocytic Leukemia. Blood 2018, 132 (Suppl. 1), 693. [CrossRef]

70. Cramer, P.; von Tresckow, J.; Bahlo, J.; Robrecht, S.; Langerbeins, P.; Al-Sawaf, O.; Engelke, A.; Fink, A.M.; Fischer, K.; Tausch, E.; et al. Bendamustine followed by obinutuzumab and venetoclax in chronic lymphocytic leukaemia (CLL2-BAG): Primary endpoint analysis of a multicentre, open-label, phase 2 trial. Lancet Oncol. 2018, 19, 1215-1228. [CrossRef]

71. Stilgenbauer, S.; Eichhorst, B.; Schetelig, J.; Hillmen, P.; Seymour, J.F.; Coutre, S.; Jurczak, W.; Mulligan, S.P.; Schuh, A.; Assouline, S.; et al. Venetoclax for Patients With Chronic Lymphocytic Leukemia with 17p Deletion: Results From the Full Population of a Phase II Pivotal Trial. J. Clin. Oncol. 2018, 36, 1973-1980. [CrossRef] [PubMed]

72. Kater, A.P.; Seymour, J.F.; Hillmen, P.; Eichhorst, B.; Langerak, A.W.; Owen, C.; Verdugo, M.; Wu, J.; Punnoose, E.A.; Jiang, Y.; et al. Fixed Duration of Venetoclax-Rituximab in Relapsed/Refractory Chronic Lymphocytic Leukemia Eradicates Minimal Residual Disease and Prolongs Survival: Post-Treatment Follow-Up of the MURANO Phase III Study. J. Clin. Oncol. 2019, 37, 269-277. [CrossRef]

73. Vandenberg, C.J.; Cory, S. ABT-199, a new Bcl-2-specific BH3 mimetic, has in vivo efficacy against aggressive Myc-driven mouse lymphomas without provoking thrombocytopenia. Blood 2013, 121, 2285-2288. [CrossRef] [PubMed] 
74. Davids, M.S.; Roberts, A.W.; Seymour, J.F.; Pagel, J.M.; Kahl, B.S.; Wierda, W.G.; Puvvada, S.; Kipps, T.J.; Anderson, M.A.; Salem, A.H.; et al. Phase I First-in-Human Study of Venetoclax in Patients With Relapsed or Refractory Non-Hodgkin Lymphoma. J. Clin. Oncol. 2017, 35, 826-833. [CrossRef] [PubMed]

75. Tam, C.S.; Anderson, M.A.; Pott, C.; Agarwal, R.; Handunnetti, S.; Hicks, R.J.; Burbury, K.; Turner, G.; Di Iulio, J.; Bressel, M.; et al. Ibrutinib plus Venetoclax for the Treatment of Mantle-Cell Lymphoma. N. Engl. J. Med. 2018, 378, 1211-1223. [CrossRef] [PubMed]

76. Zelenetz, A.D.; Salles, G.; Mason, K.D.; Casulo, C.; Le Gouill, S.; Sehn, L.H.; Tilly, H.; Cartron, G.; Chamuleau, M.E.D.; Goy, A.; et al. Venetoclax plus R- or G-CHOP in non-Hodgkin lymphoma: Results from the CAVALLI phase 1b trial. Blood 2019, 133, 1964-1976. [CrossRef]

77. Gomez-Bougie, P.; Amiot, M. Apoptotic Machinery Diversity in Multiple Myeloma Molecular Subtypes. Front. Immunol. 2013, 4, 467. [CrossRef]

78. Morales, A.A.; Kurtoglu, M.; Matulis, S.M.; Liu, J.; Siefker, D.; Gutman, D.M.; Kaufman, J.L.; Lee, K.P.; Lonial, S.; Boise, L.H. Distribution of Bim determines Mcl-1 dependence or codependence with Bcl-xL/Bcl-2 in Mcl-1-expressing myeloma cells. Blood 2011, 118, 1329-1339. [CrossRef]

79. Touzeau, C.; Dousset, C.; Le Gouill, S.; Sampath, D.; Leverson, J.D.; Souers, A.J.; Maiga, S.; Bene, M.C.; Moreau, P.; Pellat-Deceunynck, C.; et al. The Bcl-2 specific BH3 mimetic ABT-199: A promising targeted therapy for $\mathrm{t}(11 ; 14)$ multiple myeloma. Leukemia 2014, 28, 210-212. [CrossRef]

80. Kumar, S.; Kaufman, J.L.; Gasparetto, C.; Mikhael, J.; Vij, R.; Pegourie, B.; Benboubker, L.; Facon, T.; Amiot, M.; Moreau, P.; et al. Efficacy of venetoclax as targeted therapy for relapsed/refractory $\mathrm{t}(11 ; 14)$ multiple myeloma. Blood 2017, 130, 2401-2409. [CrossRef]

81. Matulis, S.M.; Gupta, V.A.; Nooka, A.K.; Hollen, H.V.; Kaufman, J.L.; Lonial, S.; Boise, L.H. Dexamethasone treatment promotes $\mathrm{Bcl}-2$ dependence in multiple myeloma resulting in sensitivity to venetoclax. Leukemia 2016, 30, 1086-1093. [CrossRef] [PubMed]

82. Qin, J.-Z.; Ziffra, J.; Stennett, L.; Bodner, B.; Bonish, B.K.; Chaturvedi, V.; Bennett, F.; Pollock, P.M.; Trent, J.M.; Hendrix, M.J.C.; et al. Proteasome Inhibitors Trigger NOXA-Mediated Apoptosis in Melanoma and Myeloma Cells. Cancer Res. 2005, 65, 6282-6293. [CrossRef] [PubMed]

83. Gomez-Bougie, P.; Wuilleme-Toumi, S.; Menoret, E.; Trichet, V.; Robillard, N.; Philippe, M.; Bataille, R.; Amiot, M. Noxa up-regulation and Mcl-1 cleavage are associated to apoptosis induction by bortezomib in multiple myeloma. Cancer Res. 2007, 67, 5418-5424. [CrossRef] [PubMed]

84. Gomez-Bougie, P.; Menoret, E.; Juin, P.; Dousset, C.; Pellat-Deceunynck, C.; Amiot, M. Noxa controls Mule-dependent Mcl-1 ubiquitination through the regulation of the Mcl-1/USP9X interaction. Biochem. Biophys. Res. Commun. 2011, 413, 460-464. [CrossRef]

85. Moreau, P.; Chanan-Khan, A.; Roberts, A.W.; Agarwal, A.B.; Facon, T.; Kumar, S.; Touzeau, C.; Punnoose, E.A.; Cordero, J.; Munasinghe, W.; et al. Promising efficacy and acceptable safety of venetoclax plus bortezomib and dexamethasone in relapsed/refractory MM. Blood 2017, 130, 2392-2400. [CrossRef]

86. Moreau, P.; Harrison, S.; Cavo, M.; De La Rubia, J.; Popat, R.; Gasparetto, C.; Hungria, V.T.M.; Salwender, H.; Suzuki, K.; Kim, I.; et al. Updated Analysis of Bellini, a Phase 3 Study of Venetoclax or Placebo in Combination with Bortezomib and Dexamethasone in Patients with Relapsed/Refractory Multiple Myeloma. Blood 2019, 134 (Suppl. 1), 1888. [CrossRef]

87. Dimopoulos, M.A.; Moreau, P.; Palumbo, A.; Joshua, D.; Pour, L.; Hajek, R.; Facon, T.; Ludwig, H.; Oriol, A.; Goldschmidt, H.; et al. Carfilzomib and dexamethasone versus bortezomib and dexamethasone for patients with relapsed or refractory multiple myeloma (ENDEAVOR): A randomised, phase 3, open-label, multicentre study. Lancet Oncol. 2016, 17, 27-38. [CrossRef]

88. Dimopoulos, M.A.; Goldschmidt, H.; Niesvizky, R.; Joshua, D.; Chng, W.-J.; Oriol, A.; Orlowski, R.Z.; Ludwig, H.; Facon, T.; Hajek, R.; et al. Carfilzomib or bortezomib in relapsed or refractory multiple myeloma (ENDEAVOR): An interim overall survival analysis of an open-label, randomised, phase 3 trial. Lancet Oncol. 2017, 18, 1327-1337. [CrossRef]

89. Costa, L.J.; Stadtmauer, E.A.; Morgan, G.J.; Monohan, G.P.; Kovacsovics, T.; Burwick, N.; Jakubowiak, A.J.; Mobasher, M.; Freise, K.; Ross, J.A.; et al. Phase 2 study of venetoclax plus carfilzomib and dexamethasone in patients with relapsed/refractory multiple myeloma. J. Clin. Oncol. 2018, 36 (Suppl. 15), 8004. [CrossRef]

90. Moreau, P.; Masszi, T.; Grzasko, N.; Bahlis, N.J.; Hansson, M.; Pour, L.; Sandhu, I.; Ganly, P.; Baker, B.W.; Jackson, S.R.; et al. Oral Ixazomib, Lenalidomide, and Dexamethasone for Multiple Myeloma. N. Engl. J. Med. 2016, 374, 1621-1634. [CrossRef] 
91. Kaufman, J.L.; Bueno, O.F.; Maciag, P.C.; Vue, J.; Westrup, S.; Pesko, J.; Ross, J.A.; Salem, A.H.; Gibbs, S.; Moreau, P.; et al. First Analysis from a Phase 1/2 Study of Venetoclax in Combination with Daratumumab and Dexamethasone, +/- Bortezomib, in Patients with Relapsed/Refractory Multiple Myeloma. Blood 2019, 134 (Suppl. 1), 925.

92. Hideshima, T.; Mitsiades, C.; Tonon, G.; Richardson, P.G.; Anderson, K.C. Understanding multiple myeloma pathogenesis in the bone marrow to identify new therapeutic targets. Nat. Rev. Cancer 2007, 7, 585-598. [CrossRef] [PubMed]

93. Mey, U.J.M.; Renner, C.; von Moos, R. Vemurafenib in combination with cobimetinib in relapsed and refractory extramedullary multiple myeloma harboring the BRAF V600E mutation. Hematol. Oncol. 2017, 35, 890-893. [CrossRef] [PubMed]

94. Castillo, J.; Allan, J.; Siddiqi, T.; Advani, R.; Keezer, A.; Gustine, J.; Meid, K.; Dubeau, T.; Lam, J.; Xu, L.; et al. Multicenter prospective phase II study of venetoclax in patients with previously treated Waldenstrom macroglobulinemia. Clin. Lymphoma Myeloma Leuk. 2019, 19, e39-e40. [CrossRef]

95. Blombery, P. Mechanisms of intrinsic and acquired resistance to venetoclax in B-cell lymphoproliferative disease. Leuk. Lymphoma 2020, 61, 257-262. [CrossRef] [PubMed]

96. Chiron, D.; Dousset, C.; Brosseau, C.; Touzeau, C.; Maiga, S.; Moreau, P.; Pellat-Deceunynck, C.; Le Gouill, S.; Amiot, M. Biological rational for sequential targeting of Bruton tyrosine kinase and Bcl-2 to overcome CD40-induced ABT-199 resistance in mantle cell lymphoma. Oncotarget 2015, 6, 8750-8759. [CrossRef] [PubMed]

97. Bodo, J.; Zhao, X.; Durkin, L.; Souers, A.J.; Phillips, D.C.; Smith, M.R.; Hsi, E.D. Acquired resistance to venetoclax (ABT-199) in t(14;18) positive lymphoma cells. Oncotarget 2016, 7, 70000-70010. [CrossRef] [PubMed]

98. Agarwal, R.; Chan, Y.C.; Tam, C.S.; Hunter, T.; Vassiliadis, D.; Teh, C.E.; Thijssen, R.; Yeh, P.; Wong, S.Q.; Ftouni, S.; et al. Dynamic molecular monitoring reveals that SWI-SNF mutations mediate resistance to ibrutinib plus venetoclax in mantle cell lymphoma. Nat. Med. 2019, 25, 119-129. [CrossRef]

99. Chueh, A.C.; Tse, J.W.T.; Dickinson, M.; Ioannidis, P.; Jenkins, L.; Togel, L.; Tan, B.; Luk, I.; Davalos-Salas, M.; Nightingale, R.; et al. ATF3 Repression of BCL-XL Determines Apoptotic Sensitivity to HDAC Inhibitors across Tumor Types. Clin. Cancer Res. 2017, 23, 5573-5584. [CrossRef]

100. Gupta, V.A.; Matulis, S.M.; Conage-Pough, J.E.; Nooka, A.K.; Kaufman, J.L.; Lonial, S.; Boise, L.H. Bone marrow microenvironment-derived signals induce Mcl-1 dependence in multiple myeloma. Blood 2017, 129, 1969-1979. [CrossRef]

101. Thijssen, R.; Slinger, E.; Weller, K.; Geest, C.R.; Beaumont, T.; van Oers, M.H.; Kater, A.P.; Eldering, E. Resistance to ABT-199 induced by microenvironmental signals in chronic lymphocytic leukemia can be counteracted by CD20 antibodies or kinase inhibitors. Haematologica 2015, 100, e302-e306. [CrossRef] [PubMed]

102. Oppermann, S.; Ylanko, J.; Shi, Y.; Hariharan, S.; Oakes, C.C.; Brauer, P.M.; Zuniga-Pflucker, J.C.; Leber, B.; Spaner, D.E.; Andrews, D.W. High-content screening identifies kinase inhibitors that overcome venetoclax resistance in activated CLL cells. Blood 2016, 128, 934-947. [CrossRef] [PubMed]

103. Chen, S.S.; Chang, B.Y.; Chang, S.; Tong, T.; Ham, S.; Sherry, B.; Burger, J.A.; Rai, K.R.; Chiorazzi, N. BTK inhibition results in impaired CXCR4 chemokine receptor surface expression, signaling and function in chronic lymphocytic leukemia. Leukemia 2016, 30, 833-843. [CrossRef] [PubMed]

104. Chang, B.Y.; Francesco, M.; De Rooij, M.F.; Magadala, P.; Steggerda, S.M.; Huang, M.M.; Kuil, A.; Herman, S.E.; Chang, S.; Pals, S.T.; et al. Egress of CD19(+)CD5(+) cells into peripheral blood following treatment with the Bruton tyrosine kinase inhibitor ibrutinib in mantle cell lymphoma patients. Blood 2013, 122, 2412-2424. [CrossRef] [PubMed]

105. Blombery, P.; Anderson, M.A.; Gong, J.N.; Thijssen, R.; Birkinshaw, R.W.; Thompson, E.R.; Teh, C.E.; Nguyen, T.; Xu, Z.; Flensburg, C.; et al. Acquisition of the Recurrent Gly101Val Mutation in BCL2 Confers Resistance to Venetoclax in Patients with Progressive Chronic Lymphocytic Leukemia. Cancer Discov. 2019, 9 , 342-353. [CrossRef]

106. Birkinshaw, R.W.; Gong, J.N.; Luo, C.S.; Lio, D.; White, C.A.; Anderson, M.A.; Blombery, P.; Lessene, G.; Majewski, I.J.; Thijssen, R.; et al. Structures of BCL-2 in complex with venetoclax reveal the molecular basis of resistance mutations. Nat. Commun. 2019, 10, 2385. [CrossRef]

107. Tausch, E.; Close, W.; Dolnik, A.; Bloehdorn, J.; Chyla, B.; Bullinger, L.; Dohner, H.; Mertens, D.; Stilgenbauer, S. Venetoclax resistance and acquired BCL2 mutations in chronic lymphocytic leukemia. Haematologica 2019, 104, e434-e437. [CrossRef] 
108. Roberts, A.W.; Huang, D.C.S.; Czabotar, P.E.; Westerman, D.A.; Seymour, J.F.; Anderson, M.A.; Conway, T.; Thijssen, R.; McBean, M.; Chen, X.; et al. Multiple BCL2 mutations cooccurring with Gly101Val emerge in chronic lymphocytic leukemia progression on venetoclax. Blood 2020, 135, 773-777.

109. Guièze, R.; Liu, V.M.; Rosebrock, D.; Jourdain, A.A.; Hernández-Sánchez, M.; Martinez Zurita, A.; Sun, J.; Ten Hacken, E.; Baranowski, K.; Thompson, P.A.; et al. Mitochondrial Reprogramming Underlies Resistance to BCL-2 Inhibition in Lymphoid Malignancies. Cancer Cell 2019, 36, 369-384.e13. [CrossRef]

110. Herling, C.D.; Abedpour, N.; Weiss, J.; Schmitt, A.; Jachimowicz, R.D.; Merkel, O.; Cartolano, M.; Oberbeck, S.; Mayer, P.; Berg, V.; et al. Clonal dynamics towards the development of venetoclax resistance in chronic lymphocytic leukemia. Nat. Commun. 2018, 9, 727. [CrossRef] [PubMed]

111. Fresquet, V.; Rieger, M.; Carolis, C.; Garcia-Barchino, M.J.; Martinez-Climent, J.A. Acquired mutations in BCL2 family proteins conferring resistance to the BH3 mimetic ABT-199 in lymphoma. Blood 2014, 123, 4111-4119. [CrossRef] [PubMed]

112. Zhao, X.; Ren, Y.; Lawlor, M.; Shah, B.D.; Park, P.M.C.; Lwin, T.; Wang, X.; Liu, K.; Wang, M.; Gao, J.; et al. BCL2 Amplicon Loss and Transcriptional Remodeling Drives ABT-199 Resistance in B Cell Lymphoma Models. Cancer Cell 2019, 35, 752-766.e9. [CrossRef] [PubMed]

113. Zhao, S.; Kanagal-Shamanna, R.; Navsaria, L.; Ok, C.Y.; Zhang, S.; Nomie, K.; Han, G.; Hao, D.; Hill, H.A.; Jiang, C.; et al. Efficacy of venetoclax in high risk relapsed mantle cell lymphoma (MCL)—Outcomes and mutation profile from venetoclax resistant MCL patients. Am. J. Hematol. 2020, 95, 623-629. [CrossRef] [PubMed]

114. Blombery, P.; Birkinshaw, R.W.; Nguyen, T.; Gong, J.N.; Thompson, E.R.; Xu, Z.; Westerman, D.A.; Czabotar, P.E.; Dickinson, M.; Huang, D.C.S.; et al. Characterization of a novel venetoclax resistance mutation (BCL2 Phe104Ile) observed in follicular lymphoma. Br. J. Haematol. 2019, 186, e188-e191. [CrossRef]

115. Glaser, S.P.; Lee, E.F.; Trounson, E.; Bouillet, P.; Wei, A.; Fairlie, W.D.; Izon, D.J.; Zuber, J.; Rappaport, A.R.; Herold, M.J.; et al. Anti-apoptotic Mcl-1 is essential for the development and sustained growth of acute myeloid leukemia. Genes Dev. 2012, 26, 120-125. [CrossRef]

116. Grabow, S.; Delbridge, A.R.; Aubrey, B.J.; Vandenberg, C.J.; Strasser, A. Loss of a Single Mcl-1 Allele Inhibits MYC-Driven Lymphomagenesis by Sensitizing Pro-B Cells to Apoptosis. Cell Rep. 2016, 14, 2337-2347. [CrossRef]

117. Tiedemann, R.E.; Zhu, Y.X.; Schmidt, J.; Shi, C.X.; Sereduk, C.; Yin, H.; Mousses, S.; Stewart, A.K. Identification of molecular vulnerabilities in human multiple myeloma cells by RNA interference lethality screening of the druggable genome. Cancer Res. 2012, 72, 757-768. [CrossRef]

118. Van Delft, M.F.; Wei, A.H.; Mason, K.D.; Vandenberg, C.J.; Chen, L.; Czabotar, P.E.; Willis, S.N.; Scott, C.L.; Day, C.L.; Cory, S.; et al. The BH3 mimetic ABT-737 targets selective Bcl-2 proteins and efficiently induces apoptosis via Bak/Bax if Mcl-1 is neutralized. Cancer Cell 2006, 10, 389-399. [CrossRef]

119. Wang, X.; Bathina, M.; Lynch, J.; Koss, B.; Calabrese, C.; Frase, S.; Schuetz, J.D.; Rehg, J.E.; Opferman, J.T. Deletion of MCL-1 causes lethal cardiac failure and mitochondrial dysfunction. Genes Dev. 2013, 27, 1351-1364. [CrossRef]

120. Thomas, R.L.; Roberts, D.J.; Kubli, D.A.; Lee, Y.; Quinsay, M.N.; Owens, J.B.; Fischer, K.M.; Sussman, M.A.; Miyamoto, S.; Gustafsson, A.B. Loss of MCL-1 leads to impaired autophagy and rapid development of heart failure. Genes Dev. 2013, 27, 1365-1377. [CrossRef]

121. Opferman, J.T.; Iwasaki,H.; Ong, C.C.; Suh, H.; Mizuno, S.; Akashi, K.; Korsmeyer, S.J. Obligate role of anti-apoptotic MCL-1 in the survival of hematopoietic stem cells. Science 2005, 307, 1101-1104. [CrossRef] [PubMed]

122. Opferman, J.T.; Letai, A.; Beard, C.; Sorcinelli, M.D.; Ong, C.C.; Korsmeyer, S.J. Development and maintenance of B and T lymphocytes requires antiapoptotic MCL-1. Nature 2003, 426, 671-676. [CrossRef] [PubMed]

123. Vikstrom, I.; Carotta, S.; Luthje, K.; Peperzak, V.; Jost, P.J.; Glaser, S.; Busslinger, M.; Bouillet, P.; Strasser, A.; Nutt, S.L.; et al. Mcl-1 Is Essential for Germinal Center Formation and B Cell Memory. Science 2010, 330, 1095-1099. [CrossRef] [PubMed]

124. Peperzak, V.; Vikstrom, I.; Walker, J.; Glaser, S.P.; LePage, M.; Coquery, C.M.; Erickson, L.D.; Fairfax, K.; Mackay, F.; Strasser, A.; et al. Mcl-1 is essential for the survival of plasma cells. Nat. Immunol. 2013, 14, 290-297. [CrossRef] [PubMed]

125. Dzhagalov, I.; Dunkle, A.; He, Y.W. The anti-apoptotic Bcl-2 family member Mcl-1 promotes T lymphocyte survival at multiple stages. J. Immunol. 2008, 181, 521-528. [CrossRef]

126. Huntington, N.D.; Puthalakath, H.; Gunn, P.; Naik, E.; Michalak, E.M.; Smyth, M.J.; Tabarias, H.; Degli-Esposti, M.A.; Dewson, G.; Willis, S.N.; et al. Interleukin 15-mediated survival of natural killer cells is determined by interactions among Bim, Noxa and Mcl-1. Nat. Immunol. 2007, 8, 856-863. [CrossRef] 
127. Omari, S.; Waters, M.; Naranian, T.; Kim, K.; Perumalsamy, A.L.; Chi, M.; Greenblatt, E.; Moley, K.H.; Opferman, J.T.; Jurisicova, A. Mcl-1 is a key regulator of the ovarian reserve. Cell Death Dis. 2015, 6, e1755. [CrossRef]

128. Tron, A.E.; Belmonte, M.A.; Adam, A.; Aquila, B.M.; Boise, L.H.; Chiarparin, E.; Cidado, J.; Embrey, K.J.; Gangl, E.; Gibbons, F.D.; et al. Discovery of Mcl-1-specific inhibitor AZD5991 and preclinical activity in multiple myeloma and acute myeloid leukemia. Nat. Commun. 2018, 9, 5341. [CrossRef]

129. Caenepeel, S.; Brown, S.P.; Belmontes, B.; Moody, G.; Keegan, K.S.; Chui, D.; Whittington, D.A.; Huang, X.; Poppe, L.; Cheng, A.C.; et al. AMG 176, a Selective MCL1 Inhibitor, Is Effective in Hematologic Cancer Models Alone and in Combination with Established Therapies. Cancer Discov. 2018, 8, 1582-1597.

130. Kotschy, A.; Szlavik, Z.; Murray, J.; Davidson, J.; Maragno, A.L.; Le Toumelin-Braizat, G.; Chanrion, M.; Kelly, G.L.; Gong, J.-N.; Moujalled, D.M.; et al. The MCL1 inhibitor S63845 is tolerable and effective in diverse cancer models. Nature 2016, 538, 477-482. [CrossRef]

131. Brennan, M.S.; Chang, C.; Tai, L.; Lessene, G.; Strasser, A.; Dewson, G.; Kelly, G.L.; Herold, M.J. Humanized Mcl-1 mice enable accurate preclinical evaluation of MCL-1 inhibitors destined for clinical use. Blood 2018, 132, 1573-1583. [CrossRef] [PubMed]

132. Hird, A.W.; Tron, A.E. Recent advances in the development of Mcl-1 inhibitors for cancer therapy. Pharmacol. Ther. 2019, 198, 59-67. [CrossRef] [PubMed]

133. Beroukhim, R.; Mermel, C.H.; Porter, D.; Wei, G.; Raychaudhuri, S.; Donovan, J.; Barretina, J.; Boehm, J.S.; Dobson, J.; Urashima, M.; et al. The landscape of somatic copy-number alteration across human cancers. Nature 2010, 463, 899-905. [CrossRef] [PubMed]

134. Amundson, S.A.; Myers, T.G.; Scudiero, D.; Kitada, S.; Reed, J.C.; Fornace, A.J., Jr. An informatics approach identifying markers of chemosensitivity in human cancer cell lines. Cancer Res. 2000, 60, 6101-6110.

135. Lessene, G.; Czabotar, P.E.; Sleebs, B.E.; Zobel, K.; Lowes, K.N.; Adams, J.M.; Baell, J.B.; Colman, P.M.; Deshayes, K.; Fairbrother, W.J.; et al. Structure-guided design of a selective BCL-X(L) inhibitor. Nat. Chem. Biol. 2013, 9, 390-397. [CrossRef] [PubMed]

136. Tao, Z.-F.; Hasvold, L.; Wang, L.; Wang, X.; Petros, A.M.; Park, C.H.; Boghaert, E.R.; Catron, N.D.; Chen, J.; Colman, P.M.; et al. Discovery of a Potent and Selective BCL-XL Inhibitor with in Vivo Activity. ACS Med. Chem. Lett. 2014, 5, 1088-1093. [CrossRef] [PubMed]

137. Leverson, J.D.; Phillips, D.C.; Mitten, M.J.; Boghaert, E.R.; Diaz, D.; Tahir, S.K.; Belmont, L.D.; Nimmer, P.; Xiao, Y.; Ma, X.M.; et al. Exploiting selective BCL-2 family inhibitors to dissect cell survival dependencies and define improved strategies for cancer therapy. Sci. Transl. Med. 2015, 7, ra40-ra279. [CrossRef] [PubMed]

138. Jin, S.; Cojocari, D.; Purkal, J.J.; Popovic, R.; Talaty, N.N.; Xiao, Y.; Solomon, L.R.; Boghaert, E.R.; Leverson, J.D.; Phillips, D.C. 5-Azacitidine Induces NOXA to Prime AML Cells for Venetoclax-Mediated Apoptosis. Clin. Cancer Res. 2020. [CrossRef] [PubMed]

139. Liu, Y.; Mondello, P.; Erazo, T.; Tannan, N.B.; Asgari, Z.; de Stanchina, E.; Nanjangud, G.; Seshan, V.E.; Wang, S.; Wendel, H.G.; et al. NOXA genetic amplification or pharmacologic induction primes lymphoma cells to BCL2 inhibitor-induced cell death. Proc. Natl. Acad. Sci. USA 2018, 115, 12034-12039. [CrossRef]

140. Merino, D.; Kelly, G.L.; Lessene, G.; Wei, A.H.; Roberts, A.W.; Strasser, A. BH3-Mimetic Drugs: Blazing the Trail for New Cancer Medicines. Cancer Cell 2018, 34, 879-891. [CrossRef]

141. Younes, A.; Heller, D.; Manova-Todorova, K.; de Stanchina, E.; Seshan, V.; Hagen, C.; Asgari, Z.; Ferreira, M.D.S.; Manzari, M.T.; Bala, N.B. Dual Inhibition of MCL1 and BCL2 in Lymphoma Using Tumor Targeted Nanoparticles. Blood 2019, 134 (Suppl. 1), 305.

142. Khan, S.; Zhang, X.; Lv, D.; Zhang, Q.; He, Y.; Zhang, P.; Liu, X.; Thummuri, D.; Yuan, Y.; Wiegand, J.S.; et al. A selective BCL-XL PROTAC degrader achieves safe and potent antitumor activity. Nat. Med. 2019, 25, 1938-1947. [CrossRef] [PubMed]

Publisher's Note: MDPI stays neutral with regard to jurisdictional claims in published maps and institutional affiliations.

(C) 2020 by the authors. Licensee MDPI, Basel, Switzerland. This article is an open access article distributed under the terms and conditions of the Creative Commons Attribution (CC BY) license (http://creativecommons.org/licenses/by/4.0/). 